NATIONAL ECONOMICS UNIVERSITY

FACULTY OF ECONOMICS
ERASMUS UNIVERSITY ROTTERDAM

INTERNATIONAL INSTITUTE OF SOCIAL STUDIES

\author{
VIETNAM-NETHERLANDS MASTER'S PROGRAM \\ IN DEVELOPMENT ECONOMICS (MDE)
}

\title{
THESIS
}

\section{The rise of research on development economics in Vietnam: Analyses and implications for the public and policymakers from SSHPA 2008-2020 dataset}

\author{
Supervisor(s): \\ DR. NGUYEN VIET CUONG, National Economics University, Hanoi, \\ Vietnam
}

Student:

HO MANH TOAN, MDE25

A thesis submitted for the Master Degree in Development Economics

at the Faculty of Economics

of National Economics University, Vietnam 
Hanoi, October 2020 


\section{TABLE OF CONTENTS}

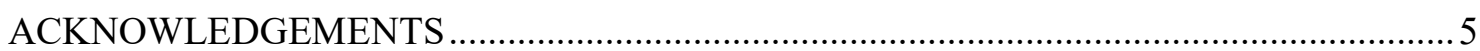

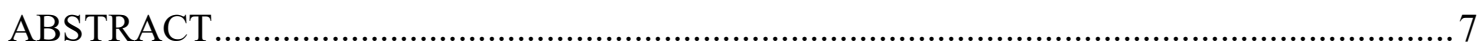

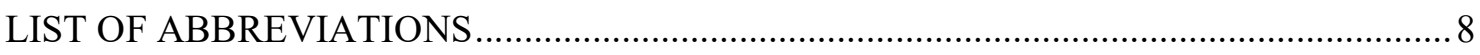

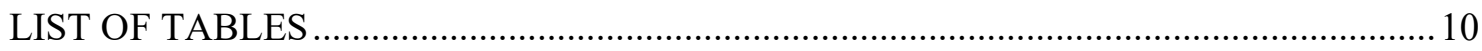

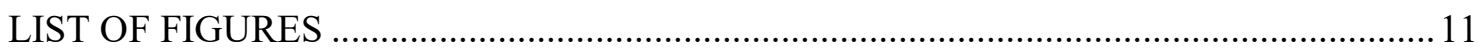

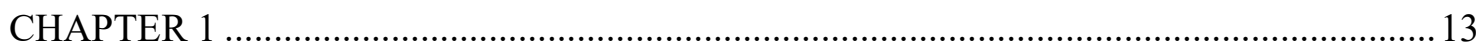

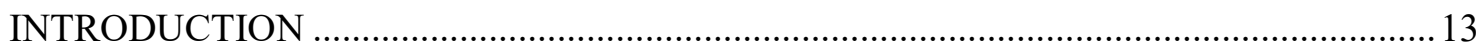

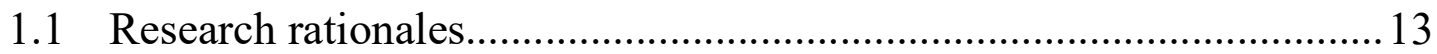

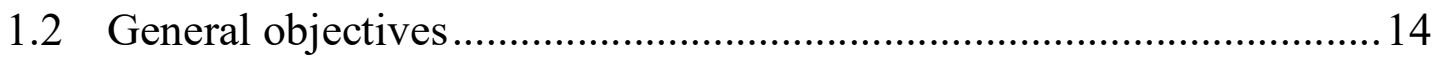

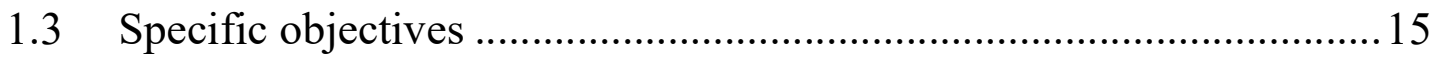

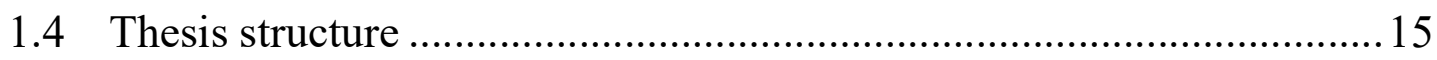

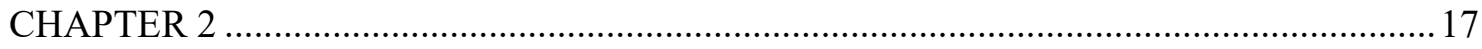

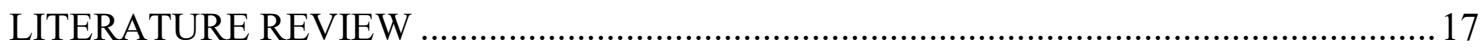

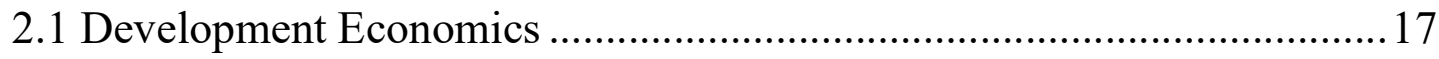

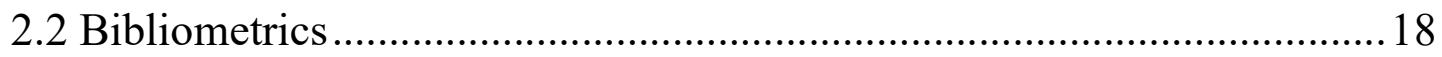

2.3 Scientific research in Vietnam ...........................................................20

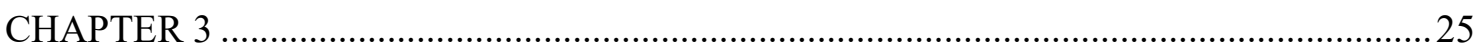

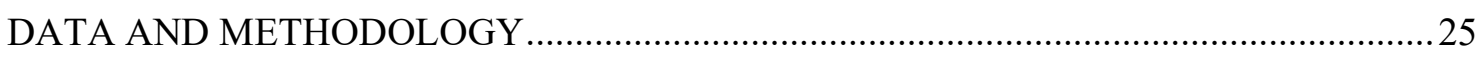

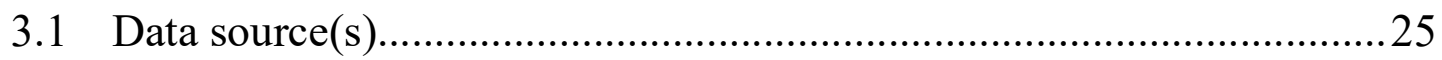

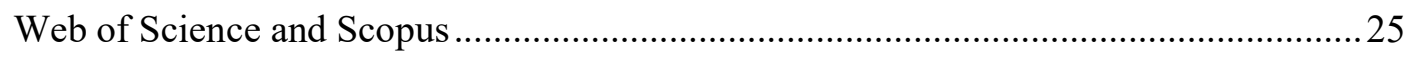

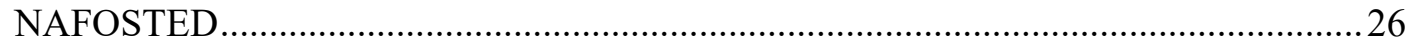

Social Sciences and Humanities Peer Awards (SSHPA) database ...................................2

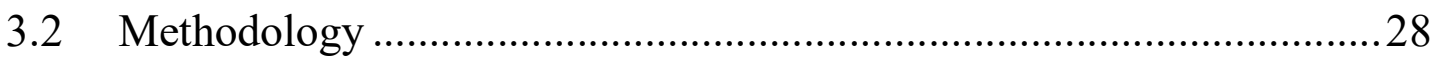

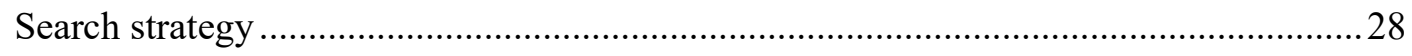




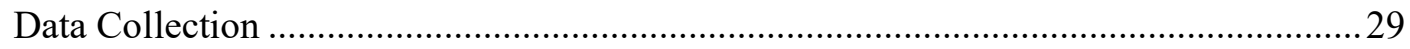

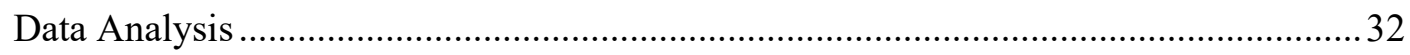

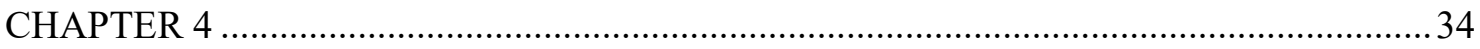

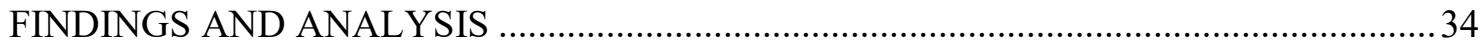

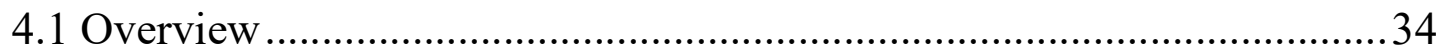

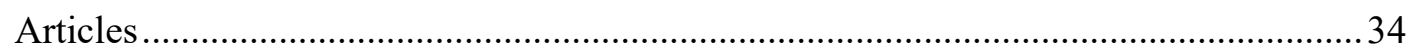

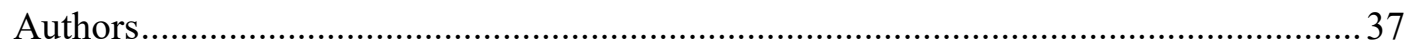

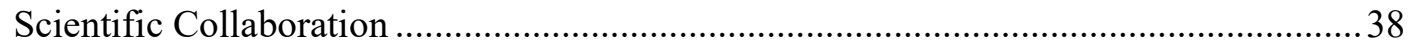

4.2 Publishing .................................................................................. 41

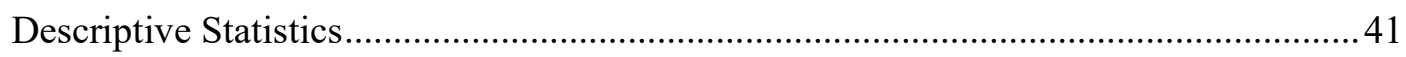

Bayesian Analysis Model [1] Open Access .......................................................... 43

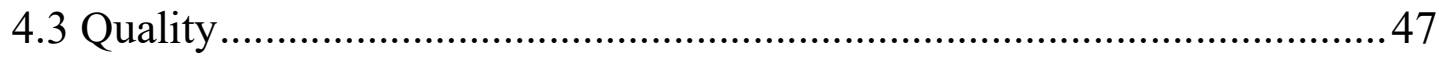

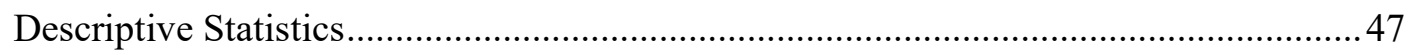

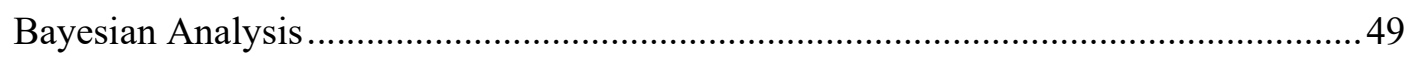

4.4 Research Topics ................................................................. 55

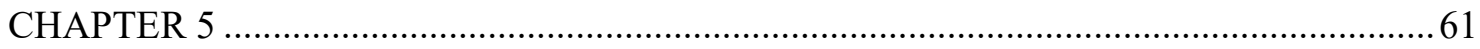

POLICY RECOMMENDATIONS AND CONCLUDING REMARKS ...............................61

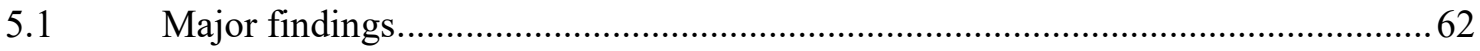

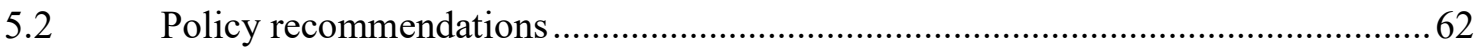

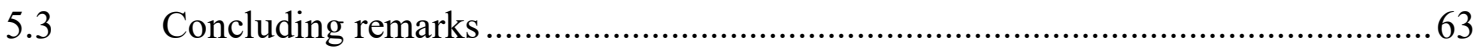

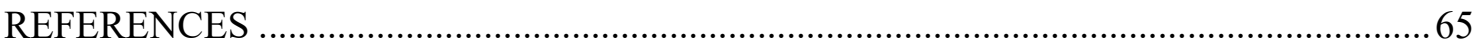




\section{ACKNOWLEDGEMENTS}

Upon the finish and submission of this thesis, I would like to express my gratitude to my advisor Professor Nguyen Viet Cuong for his guidance, suggestions, and advice since the beginning until the finishing of this thesis.

I would like to thank my older brother Ho Manh Tung and his wife Nguyen Hong Kong, my friends Nguyen Minh Hoang, Nguyen Thanh Thanh Huyen, La Viet Phuong, Nguyen Thanh Dung, Luong Anh Phuong for their support and feedback in the writing process.

In addition, I would like to express my appreciation to my friends Nguyen Ngoc Phu, Yuki Ueno, Phung Anh Hao, Hoang Minh Dong, Pham Tran Hai, Dang Minh Phuong, and Vu Thai Duy for their mental support and great friendship throughout the years.

I would like to thank my fellow classmates, especially to Do Minh Duc, Lo Trong Que, Nguyen Hai Van, Nguyen Thi Thuy Duong, Phan Thi Binh, and Nguyen To Viet Ha for the unforgettable experiences in MDE25.

I am also grateful to Professor Peter Mantello, Professor Joseph Hicks, Professor Joseph Progler and Mr. Vuong Quan Hoang for their inspiration in learning and writing. 'Teachers like you cannot be found'.

Nevertheless, I am forever in debt to my father Ho Sy Tiep and my mother Nguyen Thi Minh for their unconditioned support, love, faith and continuous encouragement throughout my years of study.

Finally, thank you for being my wife, Do Phuong Anh.

This accomplishment would not have been possible without them. Thank you.

Hanoi, October 2020

Ho Manh Toan 


\begin{abstract}
Over three decades of economic reform since 1986, Vietnam has gone from one of the poorest in the world to a lower-middle-income country. To bring the economy to the next level, science and technology development has been viewed as one of the major instruments with various new policies being introduced since 2008. Consequently, scientific publications have become an important intellectual resource. The field of development economic research also benefits from the focus on science and technology. Yet, little is known about the overall research landscape of the field. This thesis, hence, aims to fill this knowledge gap by studying a bibliometric dataset of development economic research in Vietnam from 2008 to 2020, which was extracted from The Social Sciences and Humanities Peer Awards (SSHPA) database. Descriptive and Bayesian statistics were used for analysis. We observed a steady growth of scientific publications over the years. Quantitative studies dominate the field, probably because of the availability of secondary data. The number of authors increased significantly, but the productivity is highly skewed toward the top 5\% authors, who contributed $50.61 \%$ of total publications. Collaboration pattern witnessed a significant change: less dependence on foreign colleagues and the emergence of domestic research groups. The list of journals and publishers where Vietnamese authors published the most shows high quality and reputation. Although traditional paywalled publishing is common, the result suggests that open access $(\mathrm{OA})$ is being adopted widely. In fact, OA articles tend to get more citations. Meanwhile, the citation is negatively associated with female authors and the number of Vietnamese authors. Finally, the number of foreigners in an article, and the participation of female authors tend to increase the quartile of the article.
\end{abstract}




\section{LIST OF ABBREVIATIONS}

\begin{tabular}{|l|l|}
\hline AI & Artificial Intelligence \\
\hline ASEAN & Association of Southeast Asian Nations \\
\hline ISI & Institute for Scientific Information \\
\hline JIF/IF & Journal Impact Factor \\
\hline MCMC & Hamiltonian Markov chain Monte Carlo \\
\hline NAFOSTED & National Foundation for Science and Technology Development \\
\hline SSH & Social Sciences and Humanities \\
\hline SSHPA & Social Sciences and Humanities Peer Awards \\
\hline WoS & Web of Science \\
\hline
\end{tabular}




\section{LIST OF TABLES}

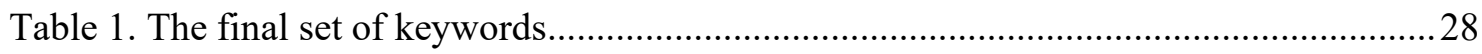

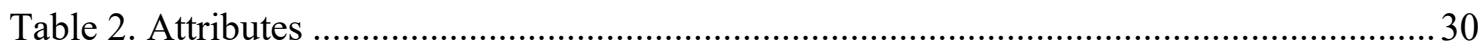

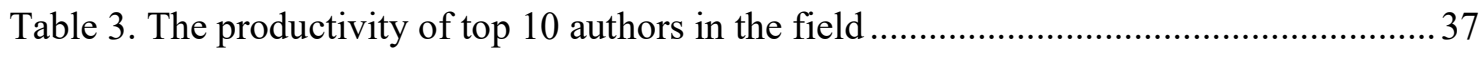

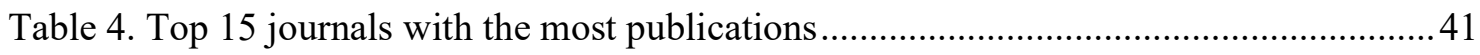

Table 5. Top 15 publishers with the most publications ..................................................... 42

Table 6. Posterior estimation of model [1] Open Access ................................................. 43

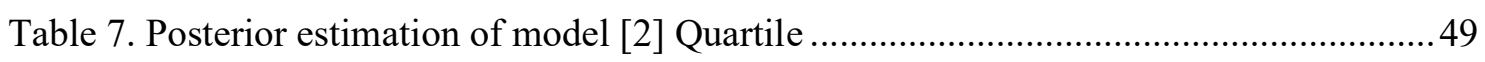

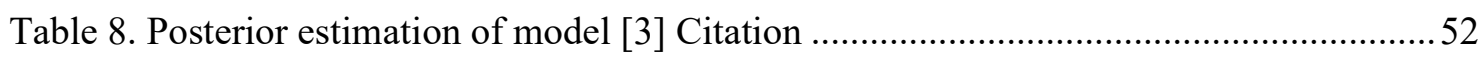

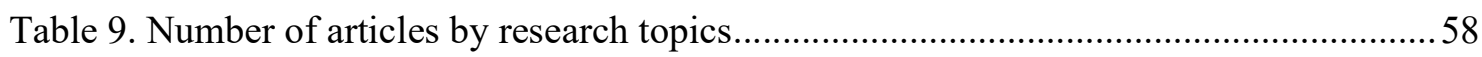




\section{LIST OF FIGURES}

Figure 1. The total number of articles in the development economics field in the 2008-2020

period. .34

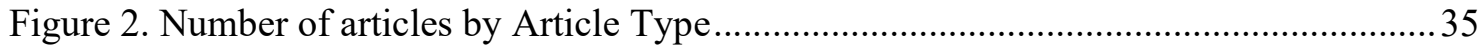

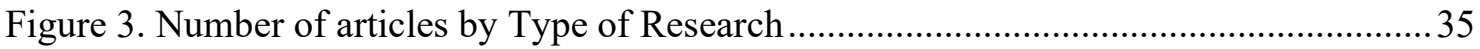

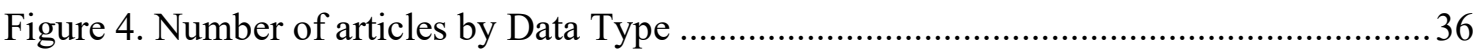

Figure 5. Number of articles by Research Location (where the research data was collected) 37 Figure 6. Number of authors published development economics papers in the 2008-2020 period

Figure 7. The international collaboration of Vietnamese development economics researchers in 2008 and 2019 (2020 was not chosen due to the incompletion of data). Note: Blue node: Vietnamese female authors; Pink node: Vietnamese male authors; Orange node: Foreign authors.

Figure 8. The international collaboration of Vietnamese development economics researchers in 2008, 2014, and 2019 (2020 was not chosen due to the incompletion of data)..................40

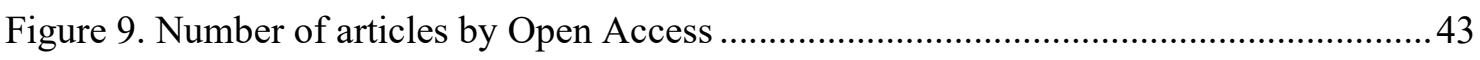

Figure 10. Visualization of MCMC chains for Model [1] Open Access ................................ 44

Figure 11. Distribution of coefficients for research location for Model [1] ..........................45

Figure 12. Distribution of coefficients of types of research: qualitative, quantitative, or

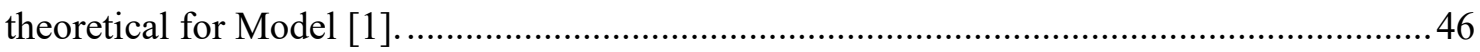

Figure 13. Distribution of coefficients of having women in the article, total number of Vietnamese/foreign authors in the article for Model [1] ................................................ 47

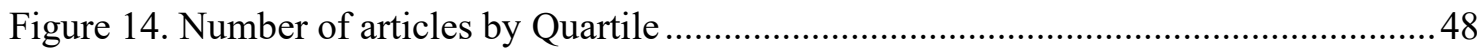

Figure 15. Distribution of citations by the number of articles .............................................. 48

Figure 16. Visualization of MCMC chains for Model [2] Quartile.......................................50

Figure 17. Distribution of coefficients for open access and research location for Model [2]. 51

Figure 18. Distribution of coefficients of having women in the article, the total number of Vietnamese/foreign authors in the article for Model [2] ...................................................52

Figure 19. Visualization of MCMC chains for Model [3] Citation ........................................53

Figure 20. Distribution of coefficients for open access and research location for Model [3]. 54

Figure 21. Distribution of coefficients of having women in the article, the total number of Vietnamese/foreign authors in the article for Model [2]. .55 
Figure 22. Dendrogram of development economics research in Vietnam in the 2008-2020

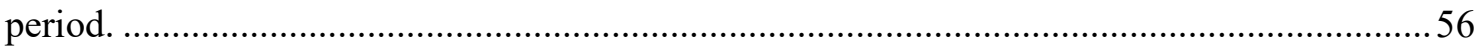

Figure 23. The connection among the most discussed topics...............................................5

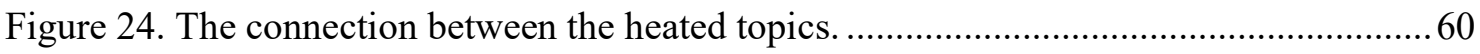

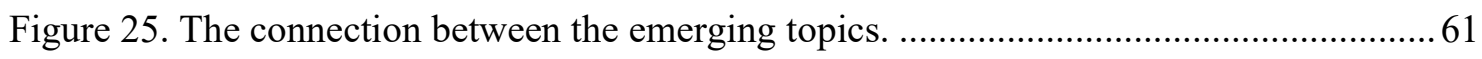




\section{CHAPTER 1}

\section{INTRODUCTION}

\subsection{Research rationales}

Vietnam's economic reformation in 1986, which is commonly called Đổi móti, transformed the country into a vibrant market economy. In 2007, the World Trade Organization recognized Vietnam as one of its members, which translated to a high inflow of foreign direct investment (FDI) of US\$71.7 billion in 2008 (Vuong, 2014). Vietnam also recorded a stable economic growth rate of $6.8 \%$ in $2017,7.1 \%$ in 2018 , and $7 \%$ in 2019 . Even under the significant impact of the COVID-19 pandemic in 2020, the country's growth rate is still expected to be around 2 to $2.5 \%$ (Thuy, 2020b). Meanwhile, Vietnam's labor productivity was around 102 million VNĐ/person in 2018, surpassed 2017 by $5.93 \%$ (KH.V, 2018). In 2019, the labor productivity of Vietnam raised to 110.4 million VNĐ/person (Trang, 2020).

The high growth rate in recent years (Thuy, 2020b, Vuong, 2014) and the swift response to crisis (La et al., 2020) have eased the uncertainties during the pandemic for Vietnam. Currently, Vietnam can continue to focus on reaching its socio-economic goals in 2020 and in the next five years. In the 2021-2025 period, Prime Minister Nguyen Xuan Phuc aims for an average 7\% GDP growth rate (Thuy, 2020a, The National Assembly of Viet Nam, 2016). The fast-growing economy has benefited many important industries in the country, including science and technology.

In 2008, the National Foundation for Science and Technology Development (NAFOSTED) gained official status after its establishment in 2003 with the Decree $122 / 2003 / \mathrm{NĐ}-\mathrm{CP}$ of the Government. Six years into its officialization, the Government issued the Decree 23/2014/NĐ-CP on 3 April 2014 to reform the rules of the NAFOSTED. Science and technology in Vietnam have taken off with a remarkable growth rate and productivity. For instance, the growth rate of scientific publications from Vietnam in the Scopus or Web of Science (WoS) has been maintained at a high level, averagely 17 - 20\% per year in the 2011 2015 period (Manh, 2015, Nguyen et al., 2017c). However, compared to the regional level, Vietnam only ranked fourth among ASEAN countries in terms of scientific productivity (Nguyen and Pham, 2011).

Thus, even though the country has achieved significant economic goals, the success did not translate to remarkable achievements in other fields such as science. However, the current 
economic achievements can be seen a foundation for future development. Thus, it is crucial for policymakers to be provided with a strong theoretical background and empirical evidence to develop suitable policies. To this end, a robust research capacity in development economics is important for Vietnam. As various studies have pointed out the causal relationship between scientific productivity and economic development (Odhiambo Nicholas and Ntenga, 2016, Kumar et al., 2016, Solarin and Yen, 2016), a thorough overview of development economics research in Vietnam can generate a lot of benefits for both the scientific community and the public.

\subsection{General objectives}

In a transition context, Vietnam has been through a long process of socio-economic development. While there has been some success, many development goals are still ahead. Thus, a thorough overview of development economics research would provide balanced perspectives on research topics, data, or theories used in development economics research in Vietnam. Moreover, the relationship between demographic factors (age, gender, affiliations, or locations) and scientific productivity, the collaboration among development economics researchers in Vietnam, are important issues that need to be examined. The study aims to achieve the following goals:

Goal 1: Providing a thorough overview of development economics research in Vietnam.

Goal 2: Studying the factors affecting the scientific publishing of development economics researchers in Vietnam.

Goal 3: Studying the factors affecting the quality of scientific papers of development economics research in Vietnam.

Goal 4: Studying the main topics in development economics research in Vietnam and their characteristics. 


\subsection{Specific objectives}

The main goals of the study can be achieved by the following steps. Firstly, a thorough literature review on the following issues needs to be conducted: (i) definition of development economics; (ii) bibliometrics studies on development economics research in the world; (iii) bibliometrics studies on science and development economics in Vietnam. Secondly, based on the literature review, a list of keywords will be created. The list has to cover important topics in development economics research.

Then, based on the availability, a popular and reliable source of data is chosen. In this study, with the focus on development economics research in Vietnam, the SSHPA database is a suitable option. On the other hand, the Web of Science and Scopus are too costly. The collected data from SSHPA database will be cleaned, verified, and cross-checked manually to ensure the quality.

In this study, descriptive statistics of various factors can demonstrate the development of the field. Meanwhile, the association between independent factors and open access or quality of publications can be analyzed through Bayesian network modeling. Based on the findings, recommendations, and proposals for changes and future policies are suggested.

\subsection{Thesis structure}

This thesis comprises five chapters, including:

\section{Chapter 1: Introduction}

This section provides the motivation behind this research by reviewing economic development in Vietnam since the Doi Moi, and the coordinated effort to increase scientific productivity. However, there is a gap of knowledge on the landscape of development economics research in Vietnam, despite its potential in supporting policymakers. The main goals of the thesis, the sub-goals, and how the research is implemented are also presented in the section.

\section{Chapter 2: Literature Review}

The literature review provides various perspectives regarding the field of development economics, bibliometric study, and scientific research in Vietnam. In the first section, the author discussed the meaning of development economics research and its potential. Then, the Bibliometrics section provided various applications of bibliometric data and methods. Finally, a comprehensive review of scientific research in Vietnam was provided. 
Bibliometric data was widely used to understand the development of development economics research worldwide (Mitra et al., 2020, Odhiambo Nicholas and Ntenga, 2016). However, most bibliometric studies on Vietnam science tended to look at a wider picture of the country's scientific scene, or at least as significant as the whole social sciences and humanities (Nguyen and Pham, 2011, Manh, 2015, Vuong and Tran, 2019). There are works that studied specific topics; however, the examined dataset was too small (Vuong et al., 2020f, Vuong et al., 2020d). Therefore, a bibliometric investigation of development economics research in Vietnam is possible and of great importance.

\section{Chapter 3: Data and Methodology}

This chapter aims to introduce the data sources and demonstrates the procedure of collecting data and strategy to search for relevant publications. This thesis extracted data from the SSHPA database using a set of keywords related to development economics. To ensure that the collected publications are relevant and reliable, the author manually read the abstract to eliminate ineligible publications. This section also provides the rationales to use Bayesian methods, which is relatively new and less used than the traditional frequentist method in social science, and the models used in this research.

\section{Chapter 4: Findings and Analysis}

The result shows the growth of scientific publications over the years. Most documents were published as original articles, so there is a lack of other publication types such as books and proceedings. The field of development economics in Vietnam is mostly consisted of quantitative research, probably due to the availability of secondary data sources. The lack of qualitative or theoretical research suggests a promising research avenue for Vietnamese authors.

In terms of authors, there is a dramatic increase in the number of authors, but half of the publications are written by the top $5 \%$ of the highest productivity. The collaboration network suggests that Vietnamese researchers have become less dependent on foreign colleagues, and they tend to form research groups consisting mostly of Vietnamese native in recent years.

The analysis of journals and publishers where Vietnamese published the most shows the preference towards reputed and high-quality journals or publishers with a long history. Open access could see the new trend since it helps Vietnamese researchers to reach a larger pool of audience and get more citations. Regarding citation, there is a negative relationship between citation and the appearance of female authors and the number of Vietnamese authors. 
Finally, the quartile of journals is affected by OA status, the number of Vietnamese authors in an article, the number of foreigners in an article, and the participation of female authors.

\section{Chapter 5: Policy Recommendations and Concluding Remarks}

Based on the findings, several recommendations are provided to policymakers as well as researchers in the field. For policymakers, the trend of publication, such as open access, should be considered. Moreover, maintaining the quality among the increasing volumes of works is a laborious task that needs support from the bibliometric database. For researchers in the field, there are still topics that need more profound contributions. Moreover, aside from quantitative results, original data, methods, or theory should be encouraged as meaningful and significant contributions.

\section{CHAPTER 2}

\section{LITERATURE REVIEW}

\subsection{Development Economics}

Development economics research in Vietnam has contributed significant studies on important topics in the country, for instance poverty identification (Nguyen and Tran, 2014), forest cover change (Van Khuc et al., 2020), social pension and aging population (Long and Pfau, 2009), natural disasters and household welfare (Arouri et al., 2015), or poverty among ethnic minorities in Vietnam (Tran et al., 2015). In a transition context with new emerging realities such as COVID-19, a review of achieved success and remained problems can help the discipline going forward. As social sciences and humanities have received more attention from society, a higher standard is necessary for Vietnamese researchers.

According to (Todaro and Smith, 2012), development economics is the study of 'how economies are transformed from stagnation to growth and from low income to high-income status and overcome problems of absolute poverty.' Development economics goes beyond the theme of efficient allocation of scarce resources in traditional economics to deal with economic, social, political, and institutional mechanisms to rapidly and widely enhance the living standards of peoples in underdeveloped and developing parts of the world. Therefore, the study of development economics should enable low-income countries to reduce poverty in 
the short term and catch up with the developed economies in the long term (Hayami et al., 2005).

Development, a normative concept, can have a wide range of meanings. Development is defined as the process of improvement concerning specific criteria or values (Colman and Nixson, 1986). From an individual perspective, development may entail sustenance (the ability to meet basic needs), self-esteem (to be a person), and freedom (to be able to choose) (Todaro and Smith, 2012, Sen, 1990, Sen, 2001). Development involves sustenance, job, and Individual development is also captured in Maslow's Hierarchy of Needs, with five levels of physiological needs, safety needs, love and belonging, esteem, and self-actualization (McLeod, 2007).

From a nation's perspective, development, which traditionally means economic growth, structural change, and trickle-down mechanisms to other social benefits, has extended to direct interventions to eliminate poverty, inequality, and unemployment (Todaro and Smith, 2012). For (Ingham, 1993, Gillis et al., 1992), the development includes economic growth, structural change, modernization, political change, decentralization \& participation, redistribution, basic needs, human development, sustainable development, and ethics. The 17 sustainable development goals have been among the most updated and comprehensive development (UNDP, 2020). There is, indeed, wide variation in the concept of development economics (McKenzie and Paffhausen, 2017).

\subsection{Bibliometrics}

The number of scientific publications has been rising considerably in recent years. More than 1 million articles are indexed in the PubMed database each year (Landhuis, 2016), and many researchers publish a paper every five days (Ioannidis et al., 2018). Thus, scientists have been using different methods to keep up with the growing volume of scientific papers. For instance, in medical research, Living Systematic Review was proposed as a practical solution to information overload (Elliott et al., 2014). In recent years, the advancement of artificial intelligence also provides experimental tools to help scientists with updating the latest findings, sorting out papers, or even supporting the peer review process (Extance, 2018, Heaven, 2018). More conventionally, the bibliometric databases like Web of Science or Scopus are still important venues for researchers. The in-depth analysis of their data can provide essential insights into the development of science (Ellegaard and Wallin, 2015). The well-known journal metrics from Web of Science and Scopus can be considered a simple type of bibliometric. However, regardless of the pure intention, using a mere number to rank a journal has many 
shortcomings and can be abused in various ways (Tran et al., 2020b, Berenbaum, 2019). Thus, in their reports, Web of Science has to use more sophisticated methods to provide an overview of the scientific development in South and East Asia (Adams et al., 2019), or to identify hot topics and new research fronts (Szomszor et al., 2020).

Employing bibliometric data, scientists have explored the development in narrow disciplines or in-depth focuses such as collaboration or productivity of a country. Lanjouw and Cockburn (2001) used PubMed data to pick up changes in research investment in tropical diseases. The study identified a shift towards more applied research on products: drug therapies or vaccines. Another example, Palomo et al. (2017) employed Scopus data to establish women, peace, and security as a multidisciplinary research area. The exploration of authors and collaboration pointed out a low level of collaboration among authors, who were already dispersed. Similarly, throughout the development of development economics research, scientists had used bibliometrics to explore different aspects of the field: the impact of prestige journals (Madrueño and Tezanos, 2018), the plans to achieve sustainable goals in different countries (Chimhowu et al., 2019), or the interdisciplinary nature of development economics (Mitra et al., 2020).

Olczyk (2016) studied 1,174 economic articles to investigate the growth pattern of the international competitiveness literature, identify the core journals and authors, the main paths of knowledge diffusion, and the critical research domains in the international competitiveness literature past 70 years. The author suggested that international trade/export performance and the impacts of cost, price, exchange rates, income, and FDI are notable research areas. However, in the last decade, the relationships between trade flows and technology, liberalization processes, environmental regulations, location, education/human capital, and productivity have become key topics. From 6,035 articles in four major journals in development economics and development studies, Madrueño and Tezanos (2018) suggested that Anglo-Saxon academia is the dominant force due to a strong geographical, institutional and linguistic bias the scientific production in the fields. The study also identified the common feature of a cross-disciplinary field in development studies.

Moreover, no specific topic is more focused than others due to the growing public concern about a wide range of issues. A citation analysis of development papers in Web of Science from 1990 to 2019 found no interdisciplinary citations between development economics and development studies. (Mitra et al., 2020). Clemens et al. (2014) observed a noticeable growth in the volume of economic papers on migration and development from the IDEAS RePEc database in the 1970-2013 period. The findings of the paper suggested the 
impact of World Bank Research Group's Research Program on International Migration and Development in 2004 + conferences on the renewed interest in migration research. Moreover, the migration research is not only limited to rural-urban migration and international remittances but also other topics such as human capital investment, global diaspora networks, circular or temporary migration, and the transfer of technology and cultural norms.

Regarding agriculture, Dias et al. (2019b) and (Dias et al., 2019a) provided a comprehensive overview of agricultural entrepreneurship literature. Based on the analysis of 110 articles until 2012 in Scopus, Dias et al. (2019a) suggested that two main themes of research were Entrepreneurial Skills and Income Sources, and Market and Resources. Meanwhile, Dias et al. (2019b) studied the 2013-2017 period and founded three leading research approaches: Entrepreneurial Skills and Behavior, Entrepreneurial Strategies, and Community and Entrepreneurial Activity. Dias et al. (2019b) also found increasing importance of developing countries, essentially in Asia, where the agricultural sector has higher economic importance.

In the study of the family business, entrepreneurship is also an important topic that has been explored extensively. Two hundred forty-one papers in Web of Science suggested that entrepreneurship and family business are emerging fields of study, with high co-citation between authors (López-Fernández et al., 2016). Currently, the topic is also being dominated by a small number of authors.

\subsection{Scientific research in Vietnam}

The earliest effort to quantify the scientific productivity of Vietnam science was in 2010. Hien (2010) compared the performance of 11 countries in East and Southeast Asia by using various factors: number of publications in Web of Science per 1 million people, mean citation count, and domestic authors' involvement in the number of peer-review international publications per 1 million people. The early findings suggested that Vietnam was among low productivity countries, with only 9.3 papers per 1 million people. Moreover, Vietnamese authors also relied heavily on international workforces, and universities in Vietnam were not involved in research productively.

In 2011, Nguyen and Pham (2011) used Web of Science data to explore the scientific publications in Southeast Asia countries in the 1991-2010 period. During the 20 years, scientists from the ASEAN countries have published 165,020 original articles in WoS indexed journals, representing $\sim 0.5 \%$ of the world's scientific output. Singapore led the region with the 
highest number of publications (accounting for $45 \%$ of the countries' total publications), followed by Thailand (21\%), Malaysia (16\%), Vietnam (6\%). At the country level, the correlation between the knowledge economy index and scientific output was 0.94 . Nguyen and Pham (2011) found a strong relationship between scientific research and the degree of "knowledgization" of the economy. Four years later, Manh (2015) used Scopus data for the 1996-2013 period. 2. Since 2002, the total output of scientific publications in Vietnam has increased by $20 \%$ annually.

However, the collaborated papers contributed about $77 \%$ of the total output, with the only exception in Mathematics. Even though the study subjects are mainly about Vietnam, Vietnamese correspond authors' percentage was very low. Japan is the largest collaborating country, followed by the United States, France, South Korea, and the United Kingdom. The United States and the United Kingdom were the largest partners with Vietnam in the medical field, especially public health. In the following year, Nguyen et al. (2017c) assessed international collaboration in Vietnam science through WoS data. Vietnam published only 200-300 papers a year in ISI indexed journals during the 1990s. However, by 2015 this number had increased more than 10-fold to almost 3000. Nevertheless, the contribution of Vietnam to the world's scientific output is still very modest (around $0.2 \%$ ) compared with the country's population size (around 1.2\% of the world's population). Moreover, similar to Manh (2015)'s findings, around $75 \%$ of the growth in Vietnam's scientific output in the past 15 years resulted from international collaborations, even though the share of internationally authored papers has slightly decreased over time.

Early works of bibliometrics from Vietnamese authors mainly used well-known databases. Moreover, the focus was not entirely on Vietnam but a regional perspective compared to other countries in East or Southeast Asia. Thus, the efforts to build an exclusive database on the scientific productivity of Vietnamese social sciences researchers has proven to be fruitful with foundational works in 2017 and early 2018 (Ho et al., 2017a, Ho et al., 2017b, Vuong et al., 2017a, Vuong et al., 2017b, Vuong et al., 2018b), a data article in 2018 (Vuong et al., 2018a), in-depth analysis of entrepreneurship research (Vuong et al., 2020f, Vuong et al., 2020d), and investigations of international publishing in Vietnam from various perspectives (Vuong et al., 2020g, Ho et al., 2020).

In 2017, using a small dataset of 412 Vietnamese authors and their works in the Scopus database, Vuong et al. (2017a) found that the gender difference in academic publications is negligible. Moreover, the productivity of researchers was found to be correlated with the number of articles in which they are corresponding authors and the seniority of the authors. 
Further analysis of researchers' contribution to a publication also indicated the importance of seniority in the productivity of Vietnamese researchers as well as the neglectable gender difference (Vuong et al., 2018b). The study further emphasized the crucial contribution of 'first authorship' in boosting the contribution.

In terms of collaboration, Vuong et al. (2017b) founded that only 33 out of 412 Vietnamese scientists in the dataset never collaborated with anyone in the 2008-2017 period. Notably, at least $65 \%$ of Vietnamese scientists had collaborated with a foreign author once in their career. However, international collaboration did not boost the total output of Vietnamese scientists by much. Meanwhile, the collaboration network of Vietnamese scientists was sparse with a high level of clustering coefficient, which indicates how likely research (a node) in the network tend to cluster together (Ho et al., 2017a, Ho et al., 2017b). The analysis of the network of Vietnamese scientists suggested that the social sciences community in Vietnam is still dominated by a few productive authors, who were productive and had good connections (Ho et al., 2017a). Thus, the preliminary network indicated that the social sciences community in Vietnam was still unsustainable in the 2008-2017 period. The results opened up a new research direction for the future.

After the preliminary results based on the initial dataset, the project published the structure behind their database, which eventually named The Social Sciences and Humanities Peer Awards (SSHPA), for peer-reviewed and further investigation (Vuong et al., 2018a). The article published the design, logical architecture, and data collection process of the database. The initial dataset of the database was collected manually by using Word and Excel. Later, a semi-structured database on the website was created to accommodate the expansion of the data. In the data article, a sample of 657 Vietnamese researchers and 1289 articles was used for validation. The database is accessible from its website: https://sshpa.com/. Currently, the database contained 4460 articles from 2772 Vietnamese authors. The numbers are continually updated to provide the most comprehensive database of Vietnamese social sciences and humanities' productivity.

Different datasets from the database were extracted to explore different aspects of Vietnamese social sciences and humanities. In late 2019, the book The Vietnamese Social Sciences at a Fork in the Road (Vuong and Tran, 2019) provided a comprehensive picture of Vietnamese social sciences and humanities through the lens of scientific publications. A dataset of 2363 articles produced by 1374 Vietnamese authors was used for in-depth analysis. Moreover, this book's contributors also interviewed 28 Vietnamese social scientists about their views on what Vietnam SSH has accomplished and where the remaining challenges lie. 
In 2020, a series of papers that stem from SSHPA data were published. Vuong et al. (2020e) analyzed how affiliations and collaboration affected the productivity of Vietnamese scientists. The study founded that researchers at universities had higher productivity than researchers based at research institutions. Then, a dataset of 111 articles in the entrepreneurship research was extracted from the SSHPA for a thorough investigation of the discipline (Vuong et al., 2020f, Vuong et al., 2020d). Vuong et al. (2020d) suggested a focus on the management side of entrepreneurship, the topics of innovation and creativity or culture is still unexplored territory. Vuong et al. (2020f) founded that Vietnamese entrepreneurship researchers still focus on practical issues rather than entrepreneurship theories. The most recent works suggested that more Vietnamese authors have been taking the leading role, and there is a shift from international collaboration to domestic collaboration (Ho et al., 2020). Moreover, Vuong et al. (2020g) suggested that Vietnamese authors have been adopting open access publishing, with the number of OA articles increased by four times in the 2008-2019 period.

In social sciences and humanities, the bibliometric data were mainly used to look at a great picture of the field. The effort to deep dive into a specific discipline or sub-discipline in SSH in Vietnam yields a humble result of only 111 articles. On the other hand, Vietnamese researchers have used large datasets from Web of Science or Scopus to investigate certain topics such as HIV research (Tran et al., 2019b, Tran et al., 2019a), quality of life of people with diabetes (Tran et al., 2020a), innovation research (Le et al., 2019), education (Vuong et al., 2020a, Hallinger and Nguyen, 2020), lakes and reservoirs (Ho and Goethals, 2020), depression among university students in East Asia (Nguyen et al., 2020a), social entrepreneurship (Tan Luc et al., 2020), non-biomedical modalities (Nguyen, 2019).

Currently, to the best of my knowledge, there is no current research investigating the landscape of development economics research in Vietnam. Therefore, this study is a pioneer work that would aim to look at the issues. Due to the nature of exploration in bibliometric studies, we aim to answer the following research questions:

RQ1: What are the development patterns of the total output, number of authors, and scientific collaboration in the Vietnamese development economics research in the 2008-2020 period?

RQ2: What are the characteristics of the scientific collaboration in Vietnamese development economics research during the 2008-2020 period? 
RQ3: What is the OA publication pattern the Vietnamese development economics research during the $2008-2020$ period?

RQ4: Do having more Vietnamese authors or international authors affect the decision to submit to OA journals?

RQ5: Do having more Vietnamese authors or international authors affect the quality of publications?

RQ6: Do having female authors affect the decision to submit to OA journals?

RQ7: Do having female authors affect the quality of publications?

RQ8: How research location and type of research affect the decision to submit to OA journals?

RQ9: How research location, type of research, and open access affect the quality of publications?

RQ10: What are the total outputs of the main research topics of the Vietnamese development economics research during the 2008-2020 period? What are their characteristics?

Regarding RQ 1 to 7, we have arrived with the following hypotheses based on the previous findings in the field:

H1: Due to the rise of scientific productivity in Vietnam, the Vietnamese development economics research in the 2008-2020 period also experience a rise in productivity, authors, and collaboration.

H2: The collaboration network of Vietnamese development economics researchers relies on international authors and some strong Vietnamese authors.

H3: We expect a high number of open access publications in the Vietnamese development economics research. 
H4: International factors such as authors or data have a considerable effect on the quality of publications, and the decision to submit to OA journals.

H5: Female authors do not have a strong effect on the quality of publications, and the decision to submit to OA journals.

\section{CHAPTER 3}

\section{DATA AND METHODOLOGY}

\subsection{Data source(s)}

The study used The Social Sciences and Humanities Peer Awards (SSHPA) database for collecting data regarding Vietnamese development economics research. SSHPA is an exclusive database recording the scientific productivity of Vietnamese social scientists and humanities researchers. A scientific publication is eligible to be included in SSHPA when they are indexed in (1) Web of Science Core Collection database, (2) Scopus database, or (3) fit the criteria for international publications issued by NAFOSTED.

\section{Web of Science and Scopus}

In 1956, the Institute for Scientific Information (ISI) was founded by Dr. Eugene Garfield. The organization quickly became famous for its products, including Web of Science (previously Web of Knowledge) or Journal Impact Factor. Web of Science, widely known in Vietnam as the ISI Web of Science or ISI for short, has become the first and the most well-known citation database globally. The database provides useful tools for librarians to identify the critical publication and its relative impacts through citation data. Capitalized Dr. Eugene Garfield's famous invention, citation index, or Journal Impact Factor, Web of Science release Journal Citation Reports annually to update the latest JIF of the journals.

Web of Science, which is currently owned by Clarivate Analytics, indexes around 24,749 journals spanning across four core collections of journals: 
- Science Citation Index Expanded (SCIE): An expansion from the original SSCI.

- Social Sciences Citation Index (SSCI): The original collection of Web of Science.

- Arts \& Humanities Citation Index (AHCI): An exclusive collection for journals in arts and humanities.

- Emerging Sources Citation Index (ESCI): An exclusive collection for new and rising journals.

Moreover, the WOS Core Collection also has the Book Citation Index (BKCI) for books and Conference Proceedings Citation Index (CPCI) for conference proceedings. At the moment, the platform tracks around 1.9 billion references from more than 171 million records, dating back from 1900 to the present.

Only until 2004 that WoS is finally challenged by Elsevier's Scopus, which is currently the largest bibliometric database of peer-reviewed publications. Scopus currently indexes around 38,192 journals, 778 conference proceedings, and 1,544 books series. Moreover, Scopus also offers Citescore, which is JIF's direct competitor, to every publication. In 2020, CiteScore decided to update its methodology by using four years. They also demonstrated their power by updating the methodology for the CiteScores in previous years as well.

Meanwhile, JIF remains unchanged, which is possibly due to the cost of restructuring its whole system. The computing power of Scopus is also demonstrated through the CiteScore tracker, a tool to keep track of CiteScore monthly. Besides the time period, Scopus also changed the types of publications counted. When CiteScore was first released, several different scholarly works, including articles, reviews, letters, notes, editorials, conference papers, and other documents, counted toward the number of total articles. Currently, Scopus has changed to only five types: articles, reviews, conference papers, book chapters, and data papers.

With their pioneer and leading positions, Scopus and Web of Science are the two most well-known databases in the world. Therefore, the Scopus and Web of Science are powerful and reliable data sources for this study. As the main goal is a wholesome picture of development economic research in Vietnam, the context of the world is crucial for making comparisons and drawing an important conclusion.

\section{NAFOSTED}

Unlike Scopus and Web of Science, the criteria for international publications in SSH issued by NAFOSTED is not a bibliometric database. They are a list of legitimate international journals 
that have been confirmed by the expert councils of NAFOSTED. The list was announced through the Decision 251/QĐ-HĐQL-NAFOSTED, issued on 11 December 2019.

The list also uses Scopus and Web of Science data. According to the list, an international journal is legitimate when: (1) it is indexed in the AHCI or SSCI core collection of the WoS database, or (2) it is indexed in the Scopus database, or (3) it is being published by famous publishers such as Springer, Elsevier, Inderscience Publishers, World Scientific, and so on, or (4) it is being published by Rank A or B publishers according to Netherlands' Research School for Socio-Economic and Natural Sciences of the Environment (SENSE), or (5) it is being published by publishers from Times Higher Education World University Rankings (THE)'s top 500 universities. Specific to Economics, only journals published by publishers from Times Higher Education World University Rankings (THE)'s top 100 universities are allowed.

Scopus and Web of Science cover most of the journals in the SSH. There are still journals that are not indexed to the databases yet, or due to the tradition of the disciplines, researchers only publish books or conference proceedings. The wide range of NAFOSTED is expected to cover the rest of the publications that Scopus and WoS might not include.

\section{Social Sciences and Humanities Peer Awards (SSHPA) database}

Web of Science (WoS) and Scopus are one of the biggest scientific databases in the world. However, when it comes to a specific country, they face several obstacles. Firstly, the speed of data update is slow. Secondly, the records could be defective due to both internal and external factors. Externally, researchers can use multiple versions of their names throughout their careers. Internally, to deal with the big data, Scopus and WoS have to use artificial intelligence to accelerate the process. However, the AI can automatically assign one person with multiple profiles due to the arbitrariness of how they input their names.

Thus, SSHPA was created to combine the best data of these three sources and address the issues for social sciences and humanities in Vietnam. The database records official scientific publications that have been produced by Vietnamese researchers from 2008 until now. Moreover, a researcher is eligible when two out of the three following criteria are satisfied:

- The researcher has Vietnamese nationality.

- The researcher is affiliated with a Vietnamese university or research institution.

- The researcher has used data from Vietnam or directly contribute to Vietnam. 
When the criteria for researchers and publications are met, a publication, such as a journal article or book, and its authors are recorded into the database. Affiliations, journals, publishers are subsequently collected to provide a thorough record. Due to its flexibility and thoroughness in organizing the data, the SSHPA database was chosen to investigate the development economics research in Vietnam. The following items comprise the data in the SSHPA database:

Author: Researchers whose scientific publications are in the SSHPA database. Based on the characteristics of the researchers in the article, we have two subsets of the author:

Publisher: The organization that published journals, books, edited books, or conference proceedings

Source includes journals, books, edited books, or conference proceedings, where an article was published

Articles is a scientific article published in a source, which can be journal articles, book chapters, or conference papers. A subset of Articles is Internationally collaborated publications, which are scientific publications in the SSHPA database with at least one author who is not Vietnamese.

$J I F$ : The annual Journal Impact Factor of a scientific journal that is indexed in Web of Science Core Collection.

\subsection{Methodology}

\section{Search strategy}

Based on the literature review, an initial set of keywords was formulated. After further consultation with experts in the field, the set of keywords was revised. Finally, the following set of keywords was used for conducting data collection.

\section{Table 1. The final set of keywords}

\begin{tabular}{|l|cl|}
\hline Groups & Keywords & \\
\hline Economic & $\bullet$ Economic growth & $\bullet$ Welfare \\
Development & $\bullet$ Natural factors & $\bullet$ Inequality \\
& $\bullet$ Human capital & $\bullet$ Labor productivity \\
& $\bullet$ Physical capital & $\bullet$ Population growth \\
& $\bullet$ technological factors & $\bullet$ Dependency burdens \\
& $\bullet$ Institutional factors & $\bullet$ Unemployment \\
\hline
\end{tabular}




\begin{tabular}{|c|c|c|}
\hline & $\begin{array}{ll}\text { - } & \text { Household income } \\
\text { - } & \text { Resource endowment } \\
\text { - } & \text { Primary market exports }\end{array}$ & $\begin{array}{ll}\text { - } & \text { Underemployment } \\
\text { - } & \text { Agricultural production }\end{array}$ \\
\hline $\begin{array}{l}\text { Development } \\
\text { Measurement }\end{array}$ & $\begin{array}{ll}\text { - } & \text { GDP and GNI per capita } \\
\text { - } & \text { purchasing power parity (PPP) } \\
\text { - } & \text { Life expectancy at birth } \\
\text { - } & \text { Infant mortality rate } \\
\text { - } & \text { Human Development Index } \\
\text { - } & \text { HDI) } \\
\text { - } & \text { Gender-related insufficiencies } \\
\text { - } & \text { index (GDI) } \\
\end{array}$ & $\begin{array}{ll}\text { - } & \text { Adult literacy rate } \\
\text { - } & \text { Net enrollment ratio in primary } \\
\text { education } \\
\text { - Composite indicators of } \\
\text { economic growth } \\
\text { - Gender empowerment measure } \\
\text { (GEM) } \\
\text { - Human poverty index (HPI) }\end{array}$ \\
\hline $\begin{array}{l}\text { International } \\
\text { Trade }\end{array}$ & $\begin{array}{ll}\text { - } & \text { Foreign Direct Investment } \\
\text { - } & \text { Import substitution } \\
\text { - } & \text { industrialization } \\
\text { - } & \text { Export promotion } \\
\text { - } & \text { Oxport-led growth } \\
\text { - } & \text { Trade liberalization }\end{array}$ & $\begin{array}{ll}\text { - } & \text { Multinational Corporation } \\
& (\mathrm{MNC}) \\
\text { - } & \text { Bilateral and regional preferential } \\
& \text { trade agreements } \\
\text { - } & \text { Diversification } \\
\text { - } & \text { Fairtrade organizations } \\
\text { - } & \text { Fairtrade Labeling Organization } \\
& \text { International (FLO) }\end{array}$ \\
\hline Aid, Debt & $\begin{array}{ll}\text { - } & \text { Humanitarian Aid } \\
\text { - } & \text { Development Aid } \\
\text { - } & \text { Official Development Assistance } \\
& \text { (ODA) } \\
\text { - } & \text { The World Bank Group } \\
\text { - } & \text { The International Monetary Fund } \\
& \text { (IMF) }\end{array}$ & \\
\hline
\end{tabular}

The main goal of the study is to provide a comprehensive picture of economic development research in Vietnam. Thus, keywords were chosen in order to create the most representative and inclusive dataset.

\section{Data Collection}

Using the final set of keywords, we searched for scientific publications in the SSHPA database from 2008 until 2020 (As of August 18, 2020). The first round of results came up with 943 
articles. Then, the author manually read the abstract to identify the most related articles. The second round of filtering resulted in 573 eligible articles. In addition to the SSHPA data, further information that are specific to development economics research was also collected:

Table 2. Attributes

\begin{tabular}{|c|c|c|}
\hline Attributes & Explanation & [Coded Number] Values \\
\hline \multirow[t]{6}{*}{ Article Type } & \multirow{6}{*}{$\begin{array}{l}\text { Type of papers that were } \\
\text { published by development } \\
\text { economics researchers. }\end{array}$} & Book \\
\hline & & Book Chapter \\
\hline & & Conference Proceedings \\
\hline & & Editorial \\
\hline & & Research Article \\
\hline & & Review \\
\hline \multirow[t]{4}{*}{ Data } & \multirow{4}{*}{$\begin{array}{l}\text { Type of data that development } \\
\text { economics researchers used to } \\
\text { conduct their studies. }\end{array}$} & $\begin{array}{l}\text { [1] Primary Data: Data collected by } \\
\text { researchers from primary sources. }\end{array}$ \\
\hline & & $\begin{array}{l}\text { [2] Secondary Data: Publica data, or data } \\
\text { collected by other people for other } \\
\text { research. }\end{array}$ \\
\hline & & [3] Both \\
\hline & & [4] Not Available \\
\hline \multirow[t]{5}{*}{ Open Access } & \multirow{5}{*}{$\begin{array}{l}\text { The way that development } \\
\text { economics researchers choose } \\
\text { to distribute their published } \\
\text { articles. }\end{array}$} & $\begin{array}{l}\text { Bronze Access: OA papers in traditional } \\
\text { journals but without any open license. }\end{array}$ \\
\hline & & $\begin{array}{l}\text { Closed Access: papers only accessible } \\
\text { with subscription or fee. }\end{array}$ \\
\hline & & $\begin{array}{l}\text { Green Access: papers only available in the } \\
\text { official repository. }\end{array}$ \\
\hline & & Gold Access: paper in OA journals. \\
\hline & & $\begin{array}{l}\text { Hybrid Access: papers with an open } \\
\text { license in a traditional journal. }\end{array}$ \\
\hline \multirow[t]{5}{*}{ Quartile } & \multirow{5}{*}{$\begin{array}{l}\text { The quality of the journal that } \\
\text { development economics } \\
\text { researchers published in, } \\
\text { according to Scimago (URL: } \\
\text { https://www.scimagojr.com/) }\end{array}$} & [1] Q1: Top 25\% journals in the list \\
\hline & & [2] Q2: Journals from $25-50 \%$ in the list \\
\hline & & [3] Q3: Journals from $50-75 \%$ in the list \\
\hline & & [4] Q4: Journals from $75-100 \%$ in the list \\
\hline & & [5] Not Available \\
\hline Research Location & $\begin{array}{l}\text { Where the data used in an article } \\
\text { was collected. }\end{array}$ & $\begin{array}{l}\text { [1] International: Data collected in other } \\
\text { countries aside from Vietnam. }\end{array}$ \\
\hline
\end{tabular}




\begin{tabular}{|c|c|c|}
\hline & & $\begin{array}{l}\text { [2] Domestic: Data collected in Vietnam } \\
\text { only. }\end{array}$ \\
\hline \multirow[t]{3}{*}{ Type of Research } & \multirow{3}{*}{$\begin{array}{l}\text { Type of analysis that } \\
\text { development economics } \\
\text { researchers used in their papers. }\end{array}$} & [1] Qualitative \\
\hline & & [2] Quantitative \\
\hline & & [3] Theory \\
\hline Citations & $\begin{array}{l}\text { The citation was obtained from } \\
\text { Google Scholar. The deadline to } \\
\text { collect the number of citations is } \\
\text { September } 12,2020 \text {. }\end{array}$ & Numerical Data \\
\hline \multirow[t]{22}{*}{ Research Topics } & \multirow{22}{*}{$\begin{array}{l}\text { Main research topics in } \\
\text { development } \\
\text { research. }\end{array}$} & Human Resource \\
\hline & & Labor Productivity \\
\hline & & Culture \\
\hline & & Economic Growth \\
\hline & & Unemployment \\
\hline & & Institution \\
\hline & & Corruption \\
\hline & & Finance \\
\hline & & Migration \\
\hline & & Sustainability/Environment \\
\hline & & Trade Liberalization \\
\hline & & Export/Import \\
\hline & & Welfare \\
\hline & & Poverty \\
\hline & & Entrepreneurship \\
\hline & & Technology Development \\
\hline & & Foreign Direct Investment (FDI) \\
\hline & & Household Income \\
\hline & & Urbanization \\
\hline & & Industrialization \\
\hline & & Inequality \\
\hline & & Natural Resources \\
\hline
\end{tabular}




\section{Data Analysis}

The study used descriptive statistics and Bayesian statistics to explore the landscape of development economics research in Vietnam. The Bayesian approach, specifically the Hamiltonian Markov chain Monte Carlo (MCMC) technique, was used to investigate the factors that might influence the decision to publish open access and the quality of the article. In essence, based on the initial dataset, the MCMC technique will simulate chains of datasets, in which each chain is independent of each other. The statistical tests will be run using the simulated dataset.

The Bayesian approach was chosen due to its capability to capture the uncertainty of decision-making in social sciences through its probabilistic inference. In social sciences, the complexity of social data and the inconsistency in different philosophies have created serious problems of reproducibility (Vuong et al., 2020b, Vuong et al., 2020c). Meanwhile, the conventional frequentist approach is also having its problems of persistent stargazing, $p$ hacking, or HARKing (Vuong et al., 2019). Thus, the Bayesian approach offers a viable alternative with clear estimation bias and powerful visualization.

In this article, two models were used for data analysis. The mathematical foundation is:

$$
\mathrm{O}_{\mathrm{i}} \sim \operatorname{alpha}\left[\mathrm{x}_{\mathrm{varint}}\right]+\text { beta }_{\mathrm{j}} * \mathrm{x}_{\mathrm{ji}}
$$

In which, the dependent response variable is $\mathrm{O}_{\mathrm{i}} ; \mathrm{x}_{\text {varint }}$ is a varying intercept variable, $\mathrm{x}_{\mathrm{j}}$ is $\mathrm{a} \mathrm{j}^{\text {th }}$ independent variable. Because $\mathrm{O}$ is a binomial variable, this variable can be expressed using the statistical distribution formula:

$$
\mathrm{O} \sim \operatorname{binomial}(\text { ilogit(theta) })
$$

In which the inverse logit function is:

$$
\operatorname{ilogit}(\text { theta })=\operatorname{logit}^{-1}\left(\alpha_{j[i]}+\beta_{i} x_{i}\right)
$$

In this study, three models was constructed by using the R statistical software (version 4.0.2) and the bayesvl package (version 0.9.5) (Vuong et al., 2020c, Vuong et al., 2020b). The estimation of weights of regression models was done in the loo package. The three models are as follows: 


\begin{tabular}{|lrr|r|}
\hline OpenAccess_bi & a_TypeofResearch[TypeofResearch] & + \\
b_ResearchLocation_OpenAccess_bi & $*$ & ResearchLocation & + \\
b_VN_Total_OpenAccess_bi $*$ VN_Total + b_F_Total_OpenAccess_bi $*$ F_Total + & \\
b_Female_bi_OpenAccess_bi $*$ Female_bi & & \\
\hline
\end{tabular}

Quartile a_TypeofResearch[TypeofResearch] + b_OpenAccess_bi_Quartile * $[2]$ OpenAccess_bi + b_ResearchLocation_Quartile * ResearchLocation + b_VN_Total_Quartile * VN_Total + b_F_Total_Quartile * F_Total + b_Female_bi_Quartile* Female_bi

\begin{tabular}{|l|l|l}
\hline AdjustCite $~$ a_TypeofResearch[TypeofResearch] + b_OpenAccess_bi_AdjustCite * & [3]
\end{tabular} OpenAccess_bi + b_ResearchLocation_AdjustCite * ResearchLocation + b_VN_Total_AdjustCite $*$ VN_Total + b_F_Total_AdjustCite * F_Total + b_Female_bi_AdjustCite * Female_bi

In these models, Type of Research, Open Access, Research Location, the number of Vietnamese authors (VN_Total), the number of foreign authors (F_Total), the participation of female authors are independent variables (Female_bi). Meanwhile, Open Access, Quartile, and Adjust Citation are dependent variables.

We have transformed some variables for the analysis:

- VN_Total: The number of Vietnamese authors in an article

- F_Total: The number of foreign authors in an article.

- Female_bi: Whether an article has female authors or not (with 1 - Yes vs. 0 - No).

- OpenAccess_bi: Open Access, which previously contained five values, has transformed into binomial data (with 1 - Yes vs. 0 - No).

- AdjustCite: The average citations of an article during the period from the published year until now. 


\section{CHAPTER 4}

\section{FINDINGS AND ANALYSIS}

Based on the keywords, 572 articles were collected in the 2008-2020 period (as of August 18, 2020). 572 articles were written by 1001 authors (684 Vietnamese authors), which were published in 317 sources from 68 publishers. According to Google Scholar, 572 articles were cited 11085 times. In the next section, we will dive into the details of these articles and authors.

\subsection{Overview}

\section{Articles}

Figure 1 presented the number of articles in the field. The number of articles had been rising steadily, with the peak in 2019 (115 articles). However, 2020 needs only 14 more to surpass 2019. As the annual growth rate of the examined period is around $23 \%$, we expect the number of articles in 2020 will surpass 2019, and this trend is likely to continue in the foreseeable future. The results suggested that $\mathrm{H} 1$ is correct.

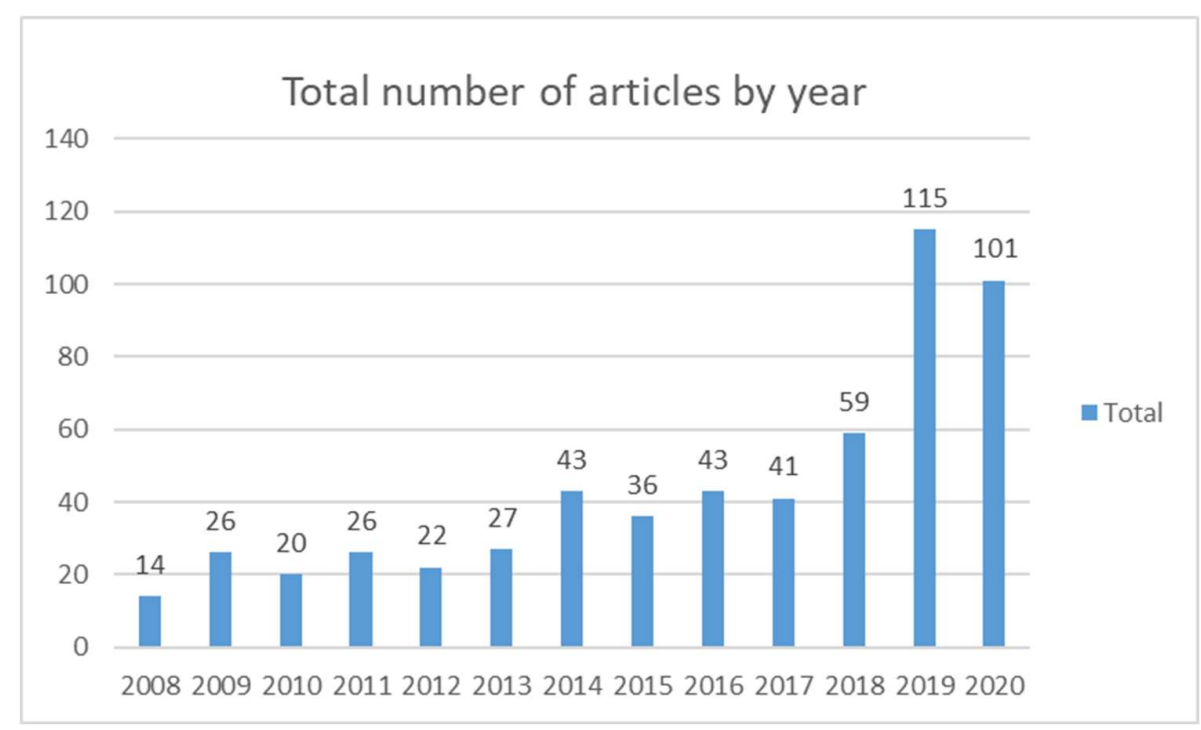

Figure 1. The total number of articles in the development economics field in the 20082020 period

The majority of development economics research is the original research article, which occupied around $91.9 \%$ of the total (see Figure 2). Meanwhile, the number of other types of 
publications is low. The number reflected the focus on publishing original research and the capacity to publish of development economics researchers. However, the lack of other types of publications is also notable. For instance, even though book is still a common way to package knowledge and discuss an issue deeply, there was only one book.

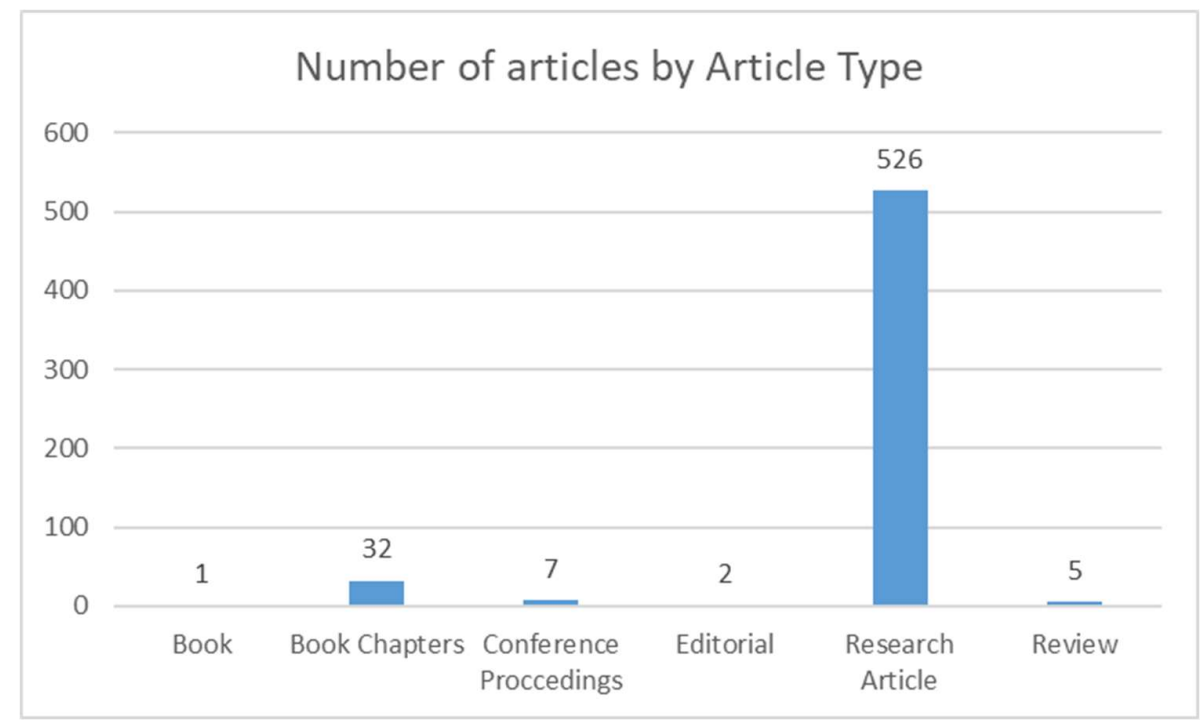

Figure 2. Number of articles by Article Type

Figure 3 presented a high number of quantitative research (462 articles). The number reflected the dominance of quantitative methods in the field. Meanwhile, a qualitative or theoretical study is still new territory for development economics researchers.

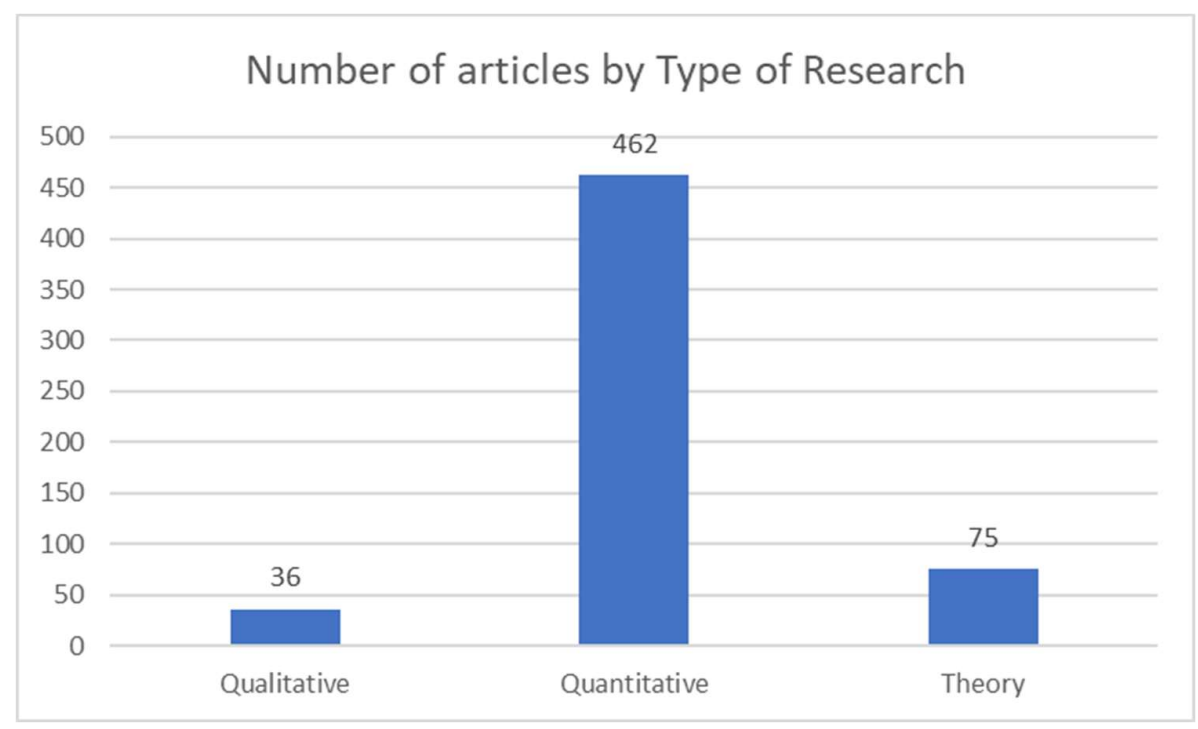

Figure 3. Number of articles by Type of Research 
The high number of quantitative studies is possibly a result of the abundance of the secondary dataset (see Figure 4). We found 377 out of 572 articles used secondary data, not to mention 18 studies used both types of data. In Vietnam, the availability of the Household Living Standards Survey, which is conducted every two years by the General Statistical Office, has created a reliable dataset for researchers (World Bank, 2020). Moreover, the effectiveness of using statistics and modeling also helps researchers to exploit the readily available data easily.

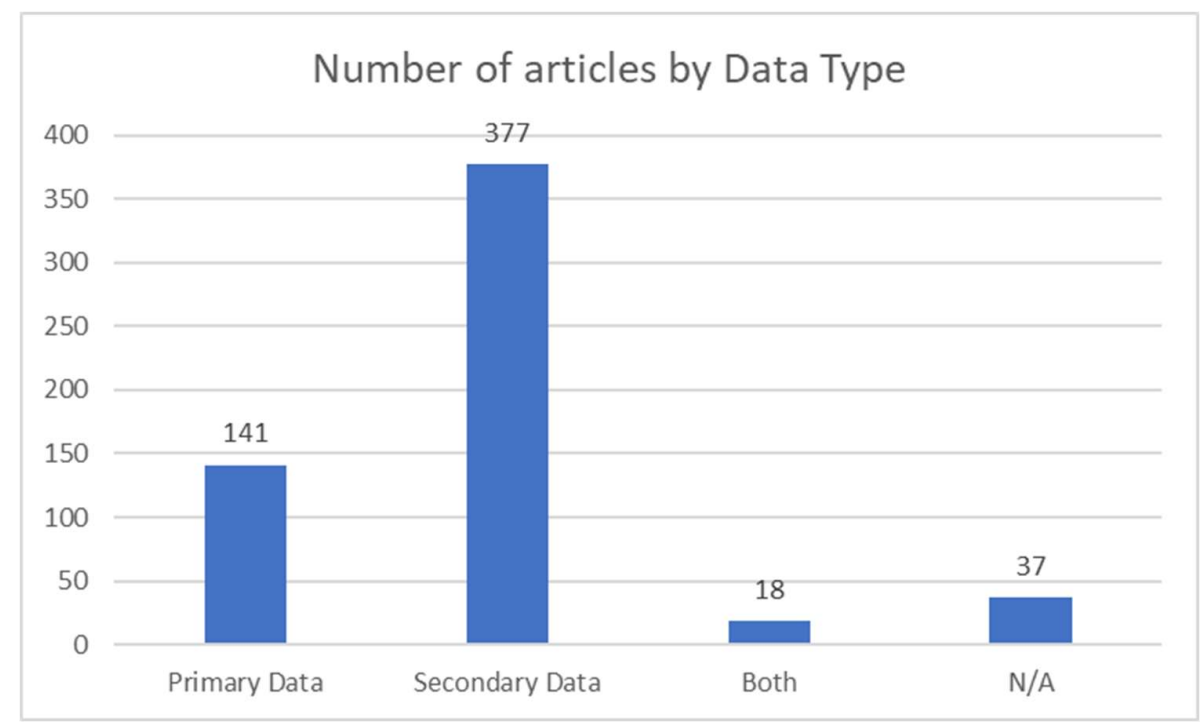

Figure 4. Number of articles by Data Type

Figure 5 showed that the research data was mainly collected in Vietnam. Only 14\% of the articles used international data.

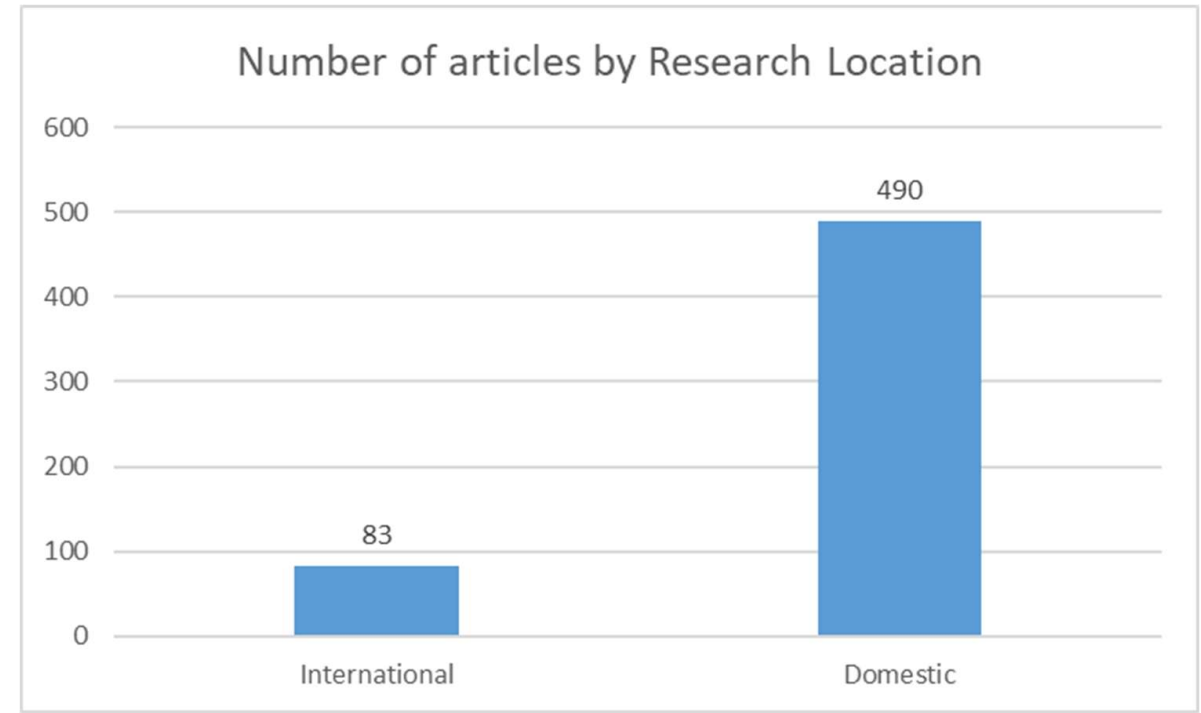




\section{Figure 5. Number of articles by Research Location (where the research data was collected)}

\section{Authors}

Figure 6 presented the number of authors who published in the development economics field from 2008 until 2020. The number had been steadily rising throughout the period, with a peak in 2019 (282 authors). However, it should be noted that the number for 2020 was only until August 18, 2020. With 241 authors in 2020, the number of authors is expected to surpass 2019. The results suggested that $\mathrm{H} 1$ is correct.

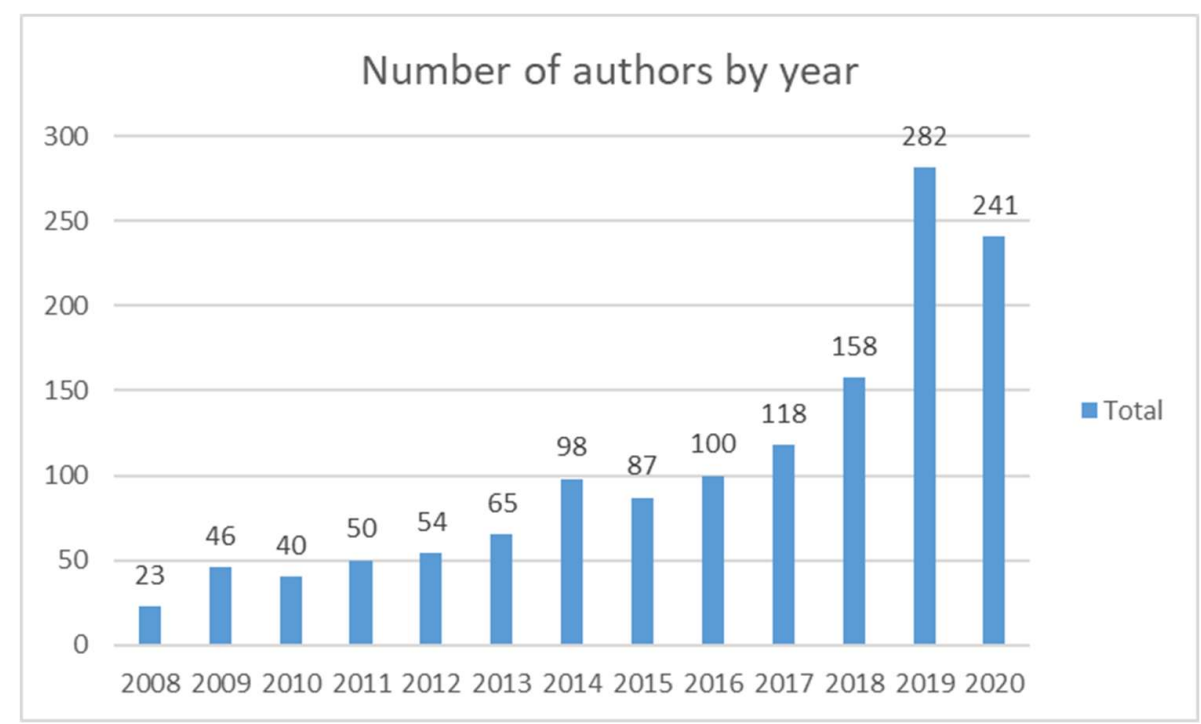

Figure 6. Number of authors published development economics papers in the 2008-2020 period

In the examined period, there were 56 out of 684 Vietnamese researchers in the top 5\% of the highest productivity in the development economics field. The top $5 \%$ of authors had 290 articles, which occupied $50.61 \%$ of the total productivity. In table 3, the top 10 authors were presented. Their names were omitted for privacy reasons.

Table 3. The productivity of top 10 authors in the field

\begin{tabular}{|c|c|}
\hline No. & Article \\
\hline 1 & 45 \\
\hline 2 & 23 \\
\hline
\end{tabular}




\begin{tabular}{|c|c|}
\hline 3 & 16 \\
\hline 4 & 13 \\
\hline 5 & 13 \\
\hline 6 & 12 \\
\hline 7 & 11 \\
\hline 8 & 11 \\
\hline 9 & 9 \\
\hline 10 & 8 \\
\hline
\end{tabular}

Notably, even within the top 10 authors, the disparity between the top half and the bottom half is significant. The top 5 authors' total output was twice the total number of the bottom half authors. The leader had around 5.6 times more articles than the last researchers in the top 10 .

\section{Scientific Collaboration}

Figure 7 presented the development of the co-author's network of Vietnam's development economics research. In 2008, the number of Vietnamese authors was insignificant (Blue and pink nodes), and the collaboration was mainly with foreigners (Orange node). Eleven years later, the network of Vietnamese authors in development economics research had matured with many research teams. In the center of 2019's network, we can see at least $2-3$ large teams, with the majority were Vietnamese authors. The network suggested that Vietnamese researchers had become more independent. Moreover, large research teams with Vietnamese authors as the leader has become more common. 


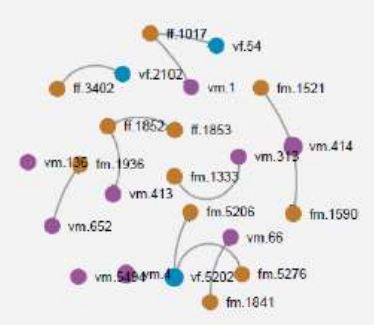

2008

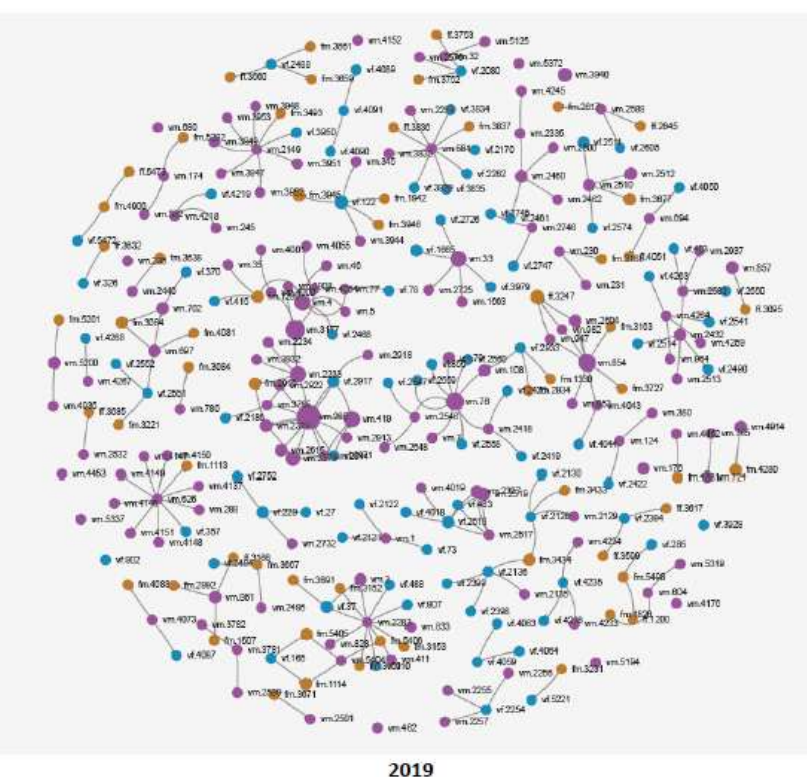

Figure 7. The international collaboration of Vietnamese development economics researchers in 2008 and 2019 (2020 was not chosen due to the incompletion of data). Note: Blue node: Vietnamese female authors; Pink node: Vietnamese male authors; Orange node: Foreign authors.

While Vietnamese authors had grown to be more independent, international collaboration was still a major contribution to the scientific productivity of Vietnamese researchers (Figure 8), which confirm H2. In 2008, there were only a few connections to other countries, such as the United States or Europe. As the total output of Vietnam grew, the map of international collaboration also grew considerably in 2014 and 2019. 

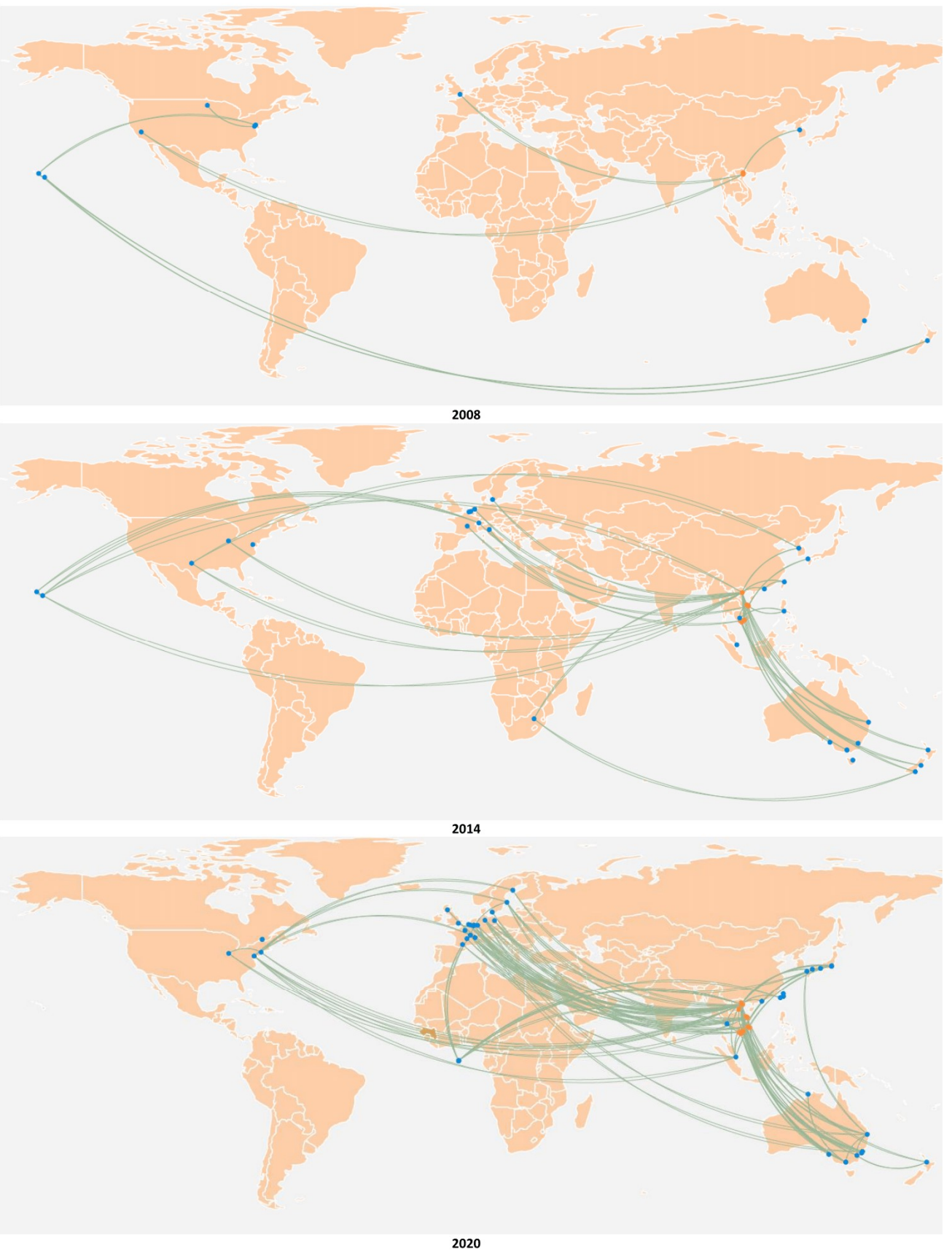

Figure 8. The international collaboration of Vietnamese development economics researchers in 2008, 2014, and 2019 (2020 was not chosen due to the incompletion of data) 
In 2014 and 2019, the international collaboration had been extended to various locations in Europe and Australia. Other cities and provinces in Vietnam also actively collaborated internationally.

In general, independent Vietnamese authors and international collaborations boosted the total output of development economics research in Vietnam in the 2008-2019 period. In the following years, this trend will continue to flourish among Vietnamese researchers.

\subsection{Publishing}

\section{Descriptive Statistics}

Tables 4 and 5 provided the lists of the top 15 journals and publishers that Vietnamese authors published the most.

\section{Table 4. Top 15 journals with the most publications}

\begin{tabular}{|l|l|l|}
\hline Journals & Article & $\begin{array}{l}\text { Quartile (as of October } \\
\mathbf{2 7 , 2 0 2 0}\end{array}$ \\
\hline Sustainability & 20 & Q2 \\
\hline Journal of the Asia Pacific Economy & 13 & Q2 \\
\hline Journal of Development Studies & 13 & Q1 \\
\hline Journal of Asian Finance, Economics and Business & 13 & Q3/Q4 \\
\hline World Development & 11 & Q1 \\
\hline Social Indicators Research & 9 & Q1/Q2 \\
\hline Journal of Risk and Financial Management & 8 & N/A \\
\hline Applied Economics & 8 & Q2 \\
\hline Management Science Letters & 7 & Q2 \\
\hline Energy Policy & 7 & Q1 \\
\hline Economies & 7 & Q2/Q3 \\
\hline Economic Analysis and Policy & 7 & Q1/Q2 \\
\hline Journal of Asian Economics & 6 & Q2 \\
\hline Global Health Action & 6 & Q1 \\
\hline Emerging Markets Finance and Trade & 6 & Q1/Q2 \\
\hline
\end{tabular}

In the top 15 journals, the quality of the journals, which is represented by Scimago's Quartile, is relatively high. There were four Q1 journals in all sections and three journals with both Q1 and Q2 sections. Moreover, Q2 journals also occupied 33\% of the list. In the top 5 journals, the majority were Q1 and Q2 journals, with highly respected journals in the field such 
as World Development (established in 1975) or Journal of Development Studies (established in 1964).

Table 5. Top 15 publishers with the most publications

\begin{tabular}{|l|l|}
\hline Publishers & Articles \\
\hline Taylor \& Francis & 103 \\
\hline Elsevier & 98 \\
\hline Springer & 71 \\
\hline Wiley & 53 \\
\hline MDPI & 43 \\
\hline Emerald & 37 \\
\hline SAGE & 21 \\
\hline Korea Distribution Science Association & 13 \\
\hline Growing Science & 10 \\
\hline World Scientific & 10 \\
\hline Inderscience & 8 \\
\hline Oxford University Press & 8 \\
\hline Canadian Center of Science and Education & 6 \\
\hline Routledge & 6 \\
\hline Cambridge University Press & 5 \\
\hline
\end{tabular}

Top 15 publishers (see Table 5) presented well-known names in the top 5 such as Taylor \& Francis, Elsevier, Springer, or Wiley. 11 out of 15 publishers were traditional ones with history and a large portfolio of scientific journals. Meanwhile, there were some new names on the list, which suggested that Vietnamese researchers are also experimenting with their choices. 


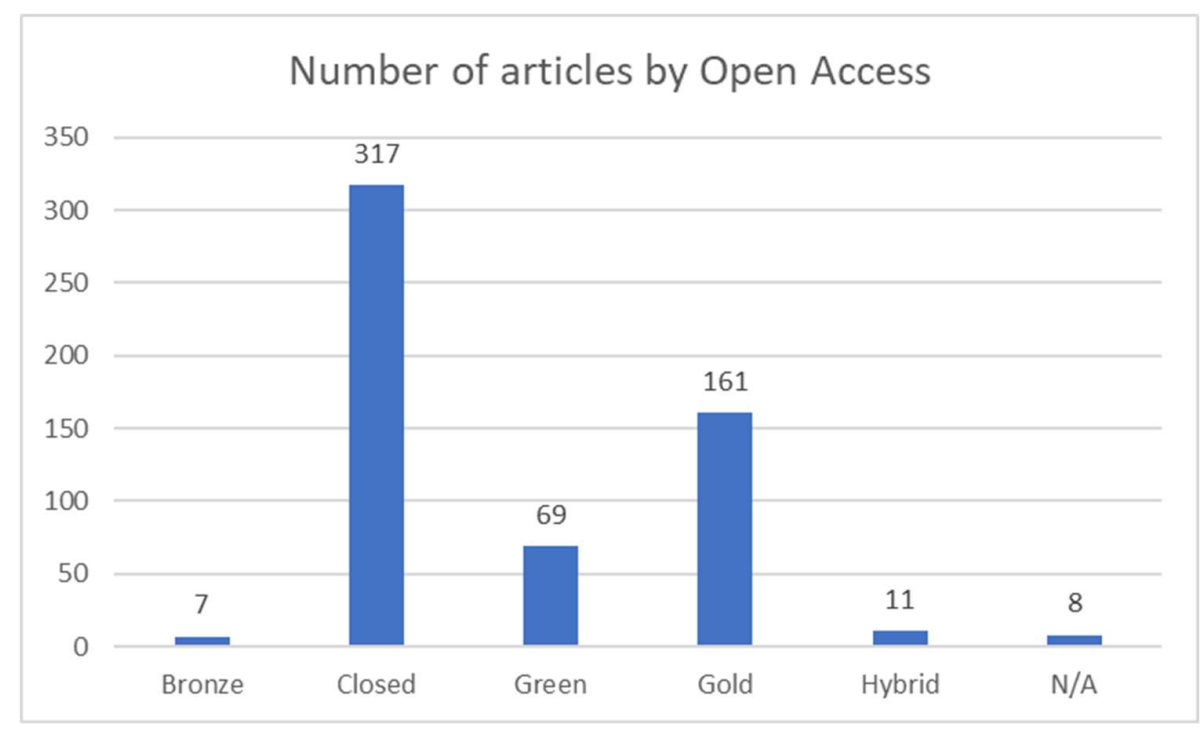

Figure 9. Number of articles by Open Access

As Table 5 suggested, most publishers were traditional ones; thus, the number of closed access articles also dominated (around 55\% of the total). Meanwhile, the open-access article in all forms occupied $43 \%$ of the total, which cannot consider a high number. Notably, the number of fully open access was relatively high: 161 articles. The number of green open access articles suggested that some Vietnamese authors have supported the OA movement and made their article available on the repository.

\section{Bayesian Analysis Model [1] Open Access}

We used the Bayesian approach to explore factors affecting the decision to publish in Open Access of the researchers. Table 6 presented the main results (mean and SD) and the technical diagnostics of the MCMC simulation: effective sample size (n_eff) and Rhat. The effective sample size is good when it has more than 1000 samples. Meanwhile, the Rhat's value is good when it is around 1. In model [1], the n_effs are larger than 1000, and the Rhat's values are 1, which means the model is converged.

Table 6. Posterior estimation of model [1] Open Access

\begin{tabular}{|l|l|l|l|l|}
\hline & Mean & SD & n_eff & Rhat \\
\hline b_ResearchLocation_OpenAccess_bi & -0.20 & 0.28 & 8880 & 1 \\
\hline b_VN_Total_OpenAccess_bi & -0.03 & 0.06 & 8800 & 1 \\
\hline b_F_Total_OpenAccess_bi & 0.04 & 0.09 & 8828 & 1 \\
\hline b_Female_bi_OpenAccess_bi & -0.33 & 0.21 & 7544 & 1 \\
\hline
\end{tabular}




\begin{tabular}{|l|l|l|l|l|}
\hline a_TypeofResearch[1] & 1.76 & 0.67 & 9401 & 1 \\
\hline a_TypeofResearch[2] & 0.68 & 0.55 & 9085 & 1 \\
\hline a_TypeofResearch[3] & 1.60 & 0.60 & 9458 & 1 \\
\hline a0_TypeofResearch & 1.34 & 1.47 & 1438 & 1 \\
\hline sigma_TypeofResearch & 1.84 & 1.99 & 2392 & 1 \\
\hline $\begin{array}{l}\text { Monte Carlo SE of elpd_loo is } 0.0 . \\
\text { All Pareto k estimates are good }(k<0.5) .\end{array}$ &
\end{tabular}

Besides effective sample size and Rhat, the Bayesian approach also allows visual diagnostics of the MCMC simulation (see Figure 10). For model 1, the simulation has four chains, each with 5000 iterations. Through the visualization in Figure 10, we can see that all chains resemble each other with no significant difference.
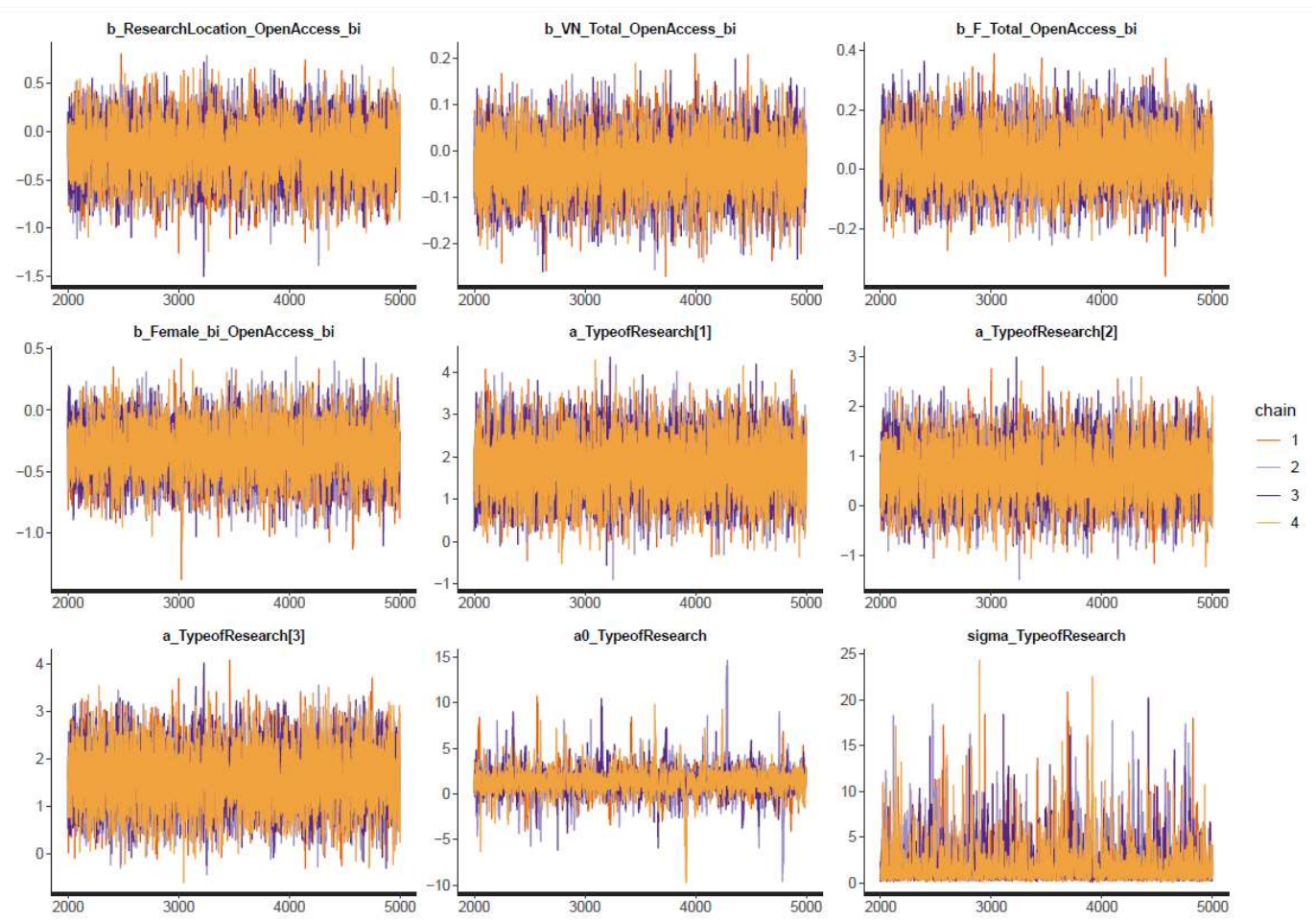

Figure 10. Visualization of MCMC chains for Model [1] Open Access

Firstly, the data used in an article that was collected in Vietnam negatively correlated with the tendency to publish open access $(\beta=-0.20$; $\mathrm{SD}=0.28)$. On the contrary, papers with international data had a higher propensity to publish in open access (See Figure 11), which confirms H4. Papers with international data tended to be 
a collaborated work between Vietnamese and international authors. Thus, as the scientific community advocates for open access, international authors might choose open access options for their articles. Meanwhile, papers with domestic data might be the work of Vietnamese authors only, who are not familiar with open access. For those who understand open access, publishing in traditional papers is still a more viable option because the OA journals are quite costly.

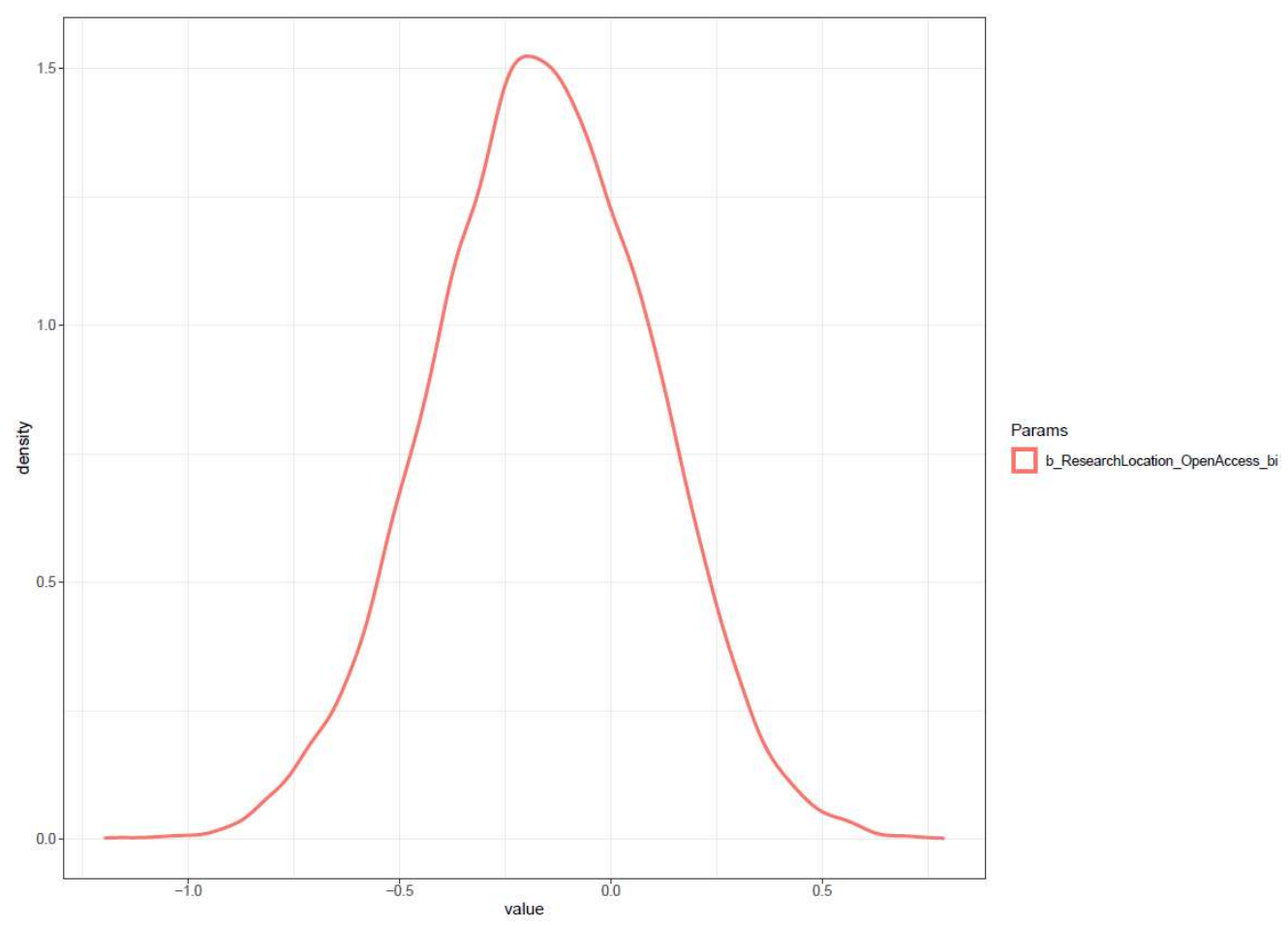

Figure 11. Distribution of coefficients for research location for Model [1].

Regarding the types of research, all three types of research: qualitative, quantitative, or theoretical did not have significant differences toward the tendency to publish open access (see Figure 12). 


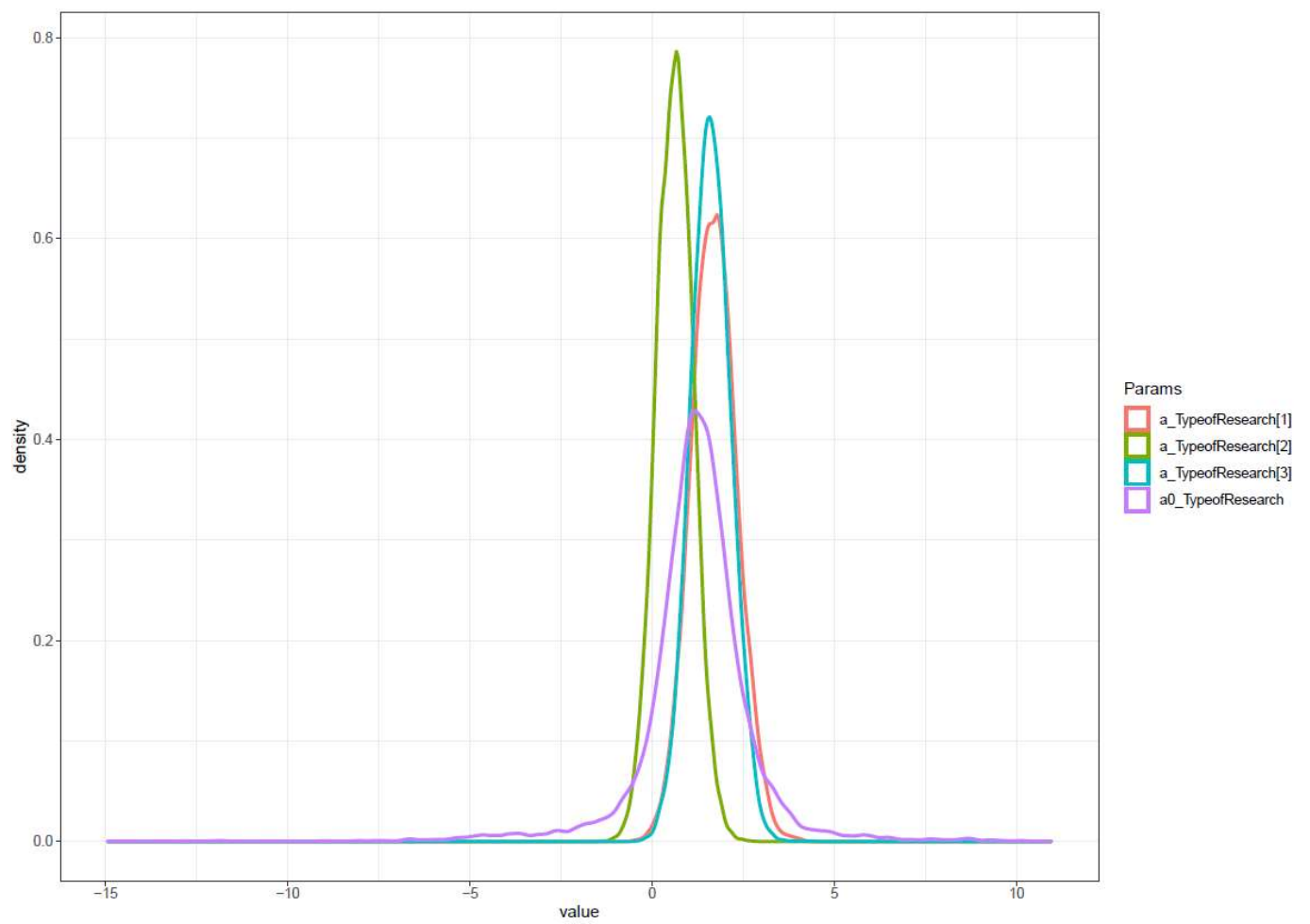

Figure 12. Distribution of coefficients of types of research: qualitative, quantitative, or theoretical for Model [1].

Finally, having a woman in the article negatively correlated with publishing OA $(\beta=-$ 0.33; $\mathrm{SD}=0.21$ ), which confirms H5. Similarly, the higher the number of Vietnamese authors in the article, the lower the tendency to publish $\mathrm{OA}(\beta=-0.03 ; \mathrm{SD}=0.06)$. The results agreed with the difference between papers used international data and papers used domestic data. 


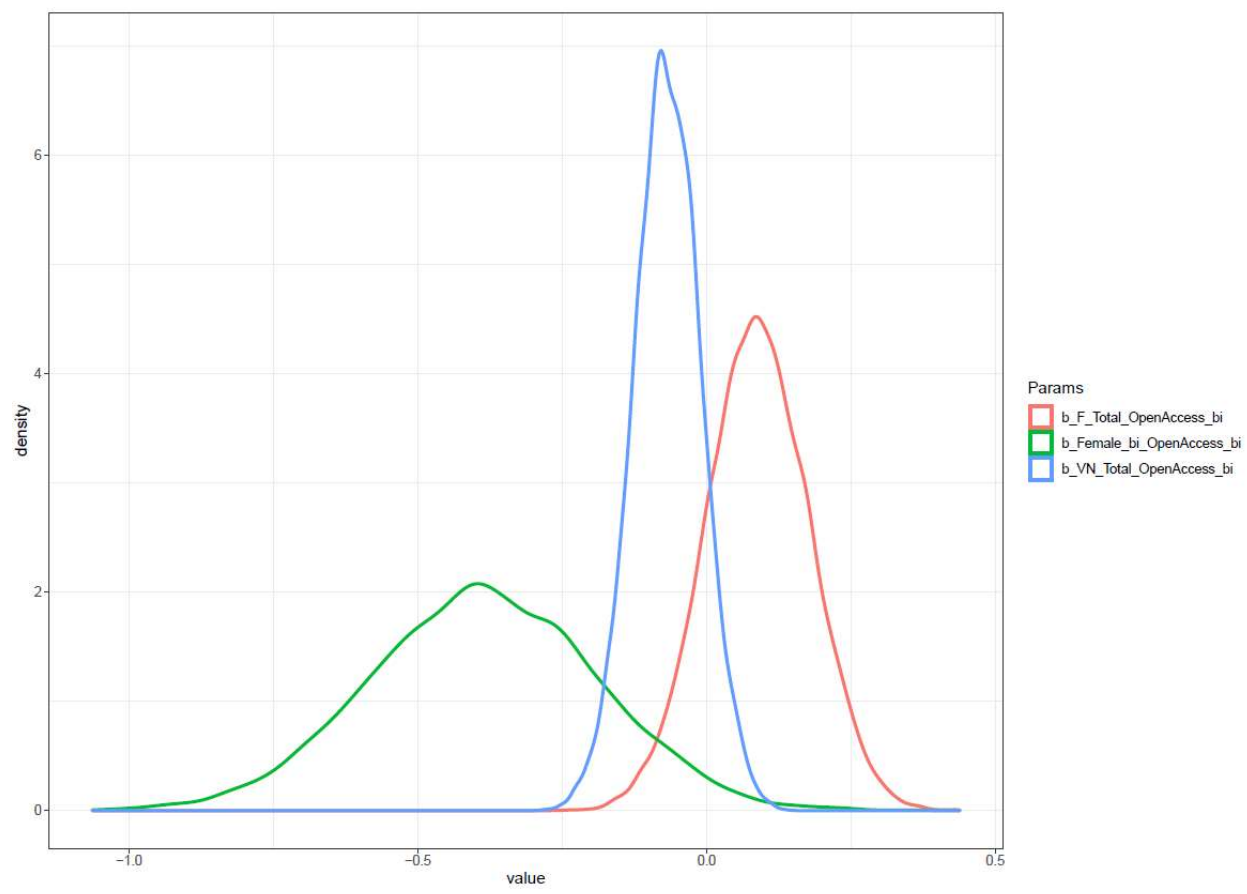

Figure 13. Distribution of coefficients of having women in the article, total number of Vietnamese/foreign authors in the article for Model [1].

In general, having international factors in the article, whether using international data or collaborating with international authors, will increase the likelihood of publishing in open access journals.

\subsection{Quality}

\section{Descriptive Statistics}

Figure 14 showed the distribution of quartiles among the examined articles. Surprisingly, many of the articles fell into the Q1 and Q2 categories (around 59\% of the total). Presumably, these two categories are higher quality journals. The results suggested that development issues in Vietnam are unique enough to attract the attention of high-quality journals in the field. 


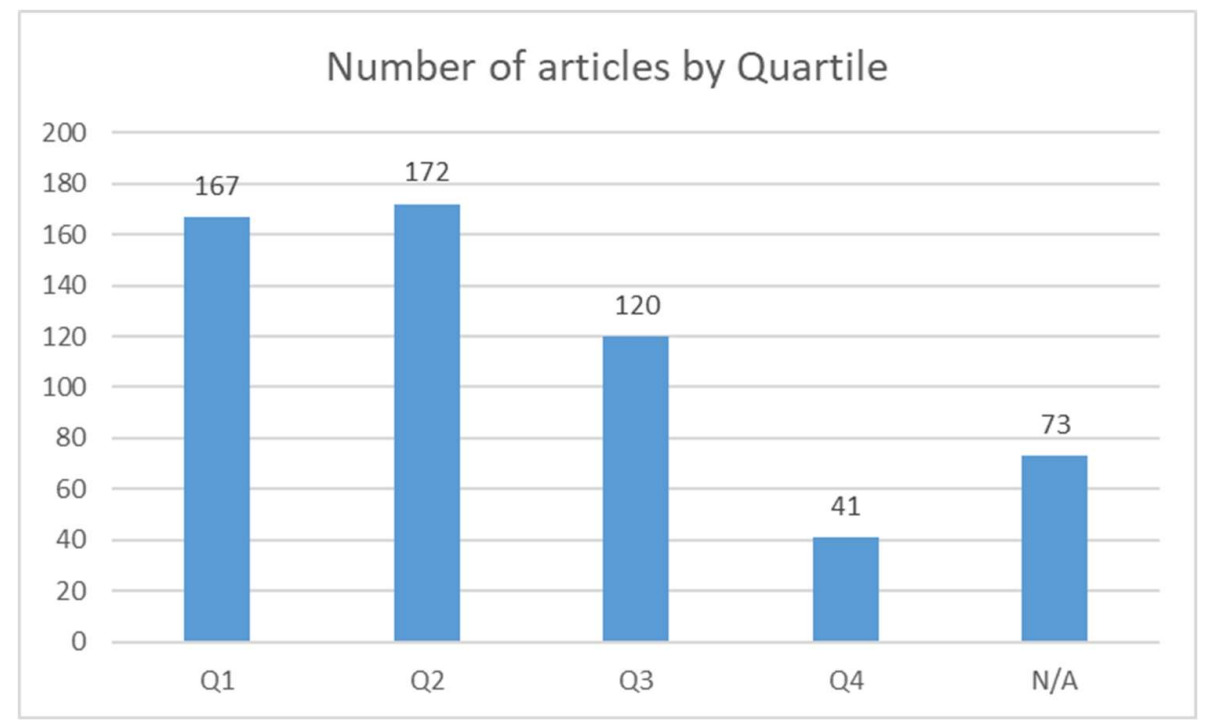

Figure 14. Number of articles by Quartile

However, the number of citations is a different story. The most cited article, which was published in 2010, had 311 citations (Anwar and Nguyen, 2010). Meanwhile, the majority of articles only had from 0 to 10 citations (see Figure 15). However, the raw number of citations did not account for when the article was published. Thus, we created a new variable by dividing the citations that an article had for the period since its publications. In this way, the most cited article was published in 2014, and it needed only six years to attain 266 citations (Khai, 2014).

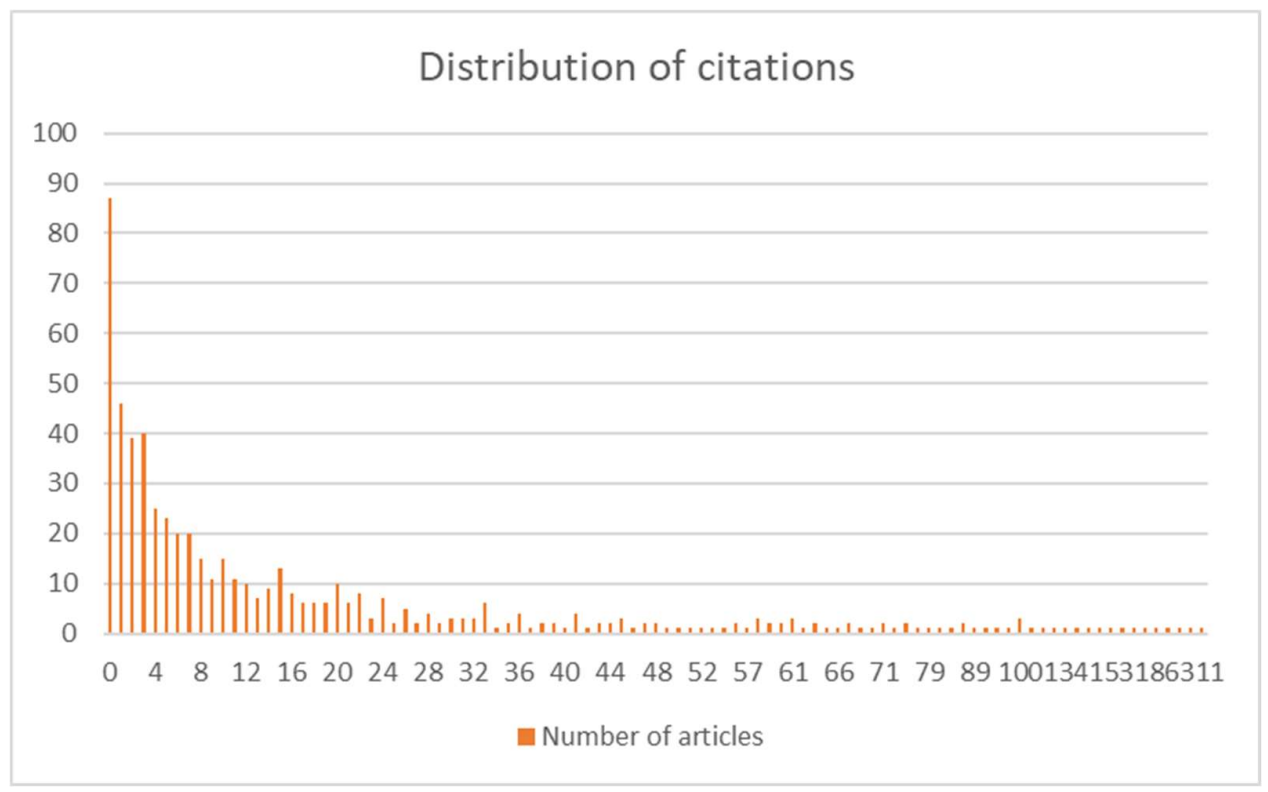

Figure 15. Distribution of citations by the number of articles 
Bayesian Analysis

Model [2] Quartile

The Bayesian regression model was used to find the correlation between open access, research location, authors, type of research, and the quartile of an article. For model [2], the effective sample sizes are all above 1000, and Rhat's values are 1. Thus, the model achieved good convergence. The loo test also suggested that the model is good (see Table 7).

Table 7. Posterior estimation of model [2] Quartile

\begin{tabular}{|l|l|l|l|l|}
\hline & Mean & SD & n_eff & Rhat \\
\hline b_OpenAccess_bi_Quartile & -0.38 & 0.12 & 10819 & 1.00 \\
\hline b_ResearchLocation_Quartile & -0.07 & 0.16 & 11319 & 1.00 \\
\hline b_VN_Total_Quartile & -0.02 & 0.04 & 10361 & 1.00 \\
\hline b_F_Total_Quartile & -0.30 & 0.06 & 9837 & 1.00 \\
\hline b_Female_bi_Quartile & -0.15 & 0.13 & 9251 & 1.00 \\
\hline a_TypeofResearch[1] & 2.94 & 0.39 & 11416 & 1.00 \\
\hline a_TypeofResearch[2] & 2.97 & 0.33 & 11491 & 1.00 \\
\hline a_TypeofResearch[3] & 3.89 & 0.35 & 11181 & 1.00 \\
\hline a0_TypeofResearch & 3.24 & 1.54 & 694 & 1.01 \\
\hline sigma_TypeofResearch & 1.80 & 2.16 & 966 & 1.00 \\
\hline $\begin{array}{l}\text { Monte Carlo SE of elpd_loo is } 0.0 . \\
\text { All Pareto } k \text { estimates are good }(k<0.5) .\end{array}$ & & & \\
\hline
\end{tabular}

Visual diagnostics of the MCMC chains for model [2] also showed good convergence (See Figure 16. 

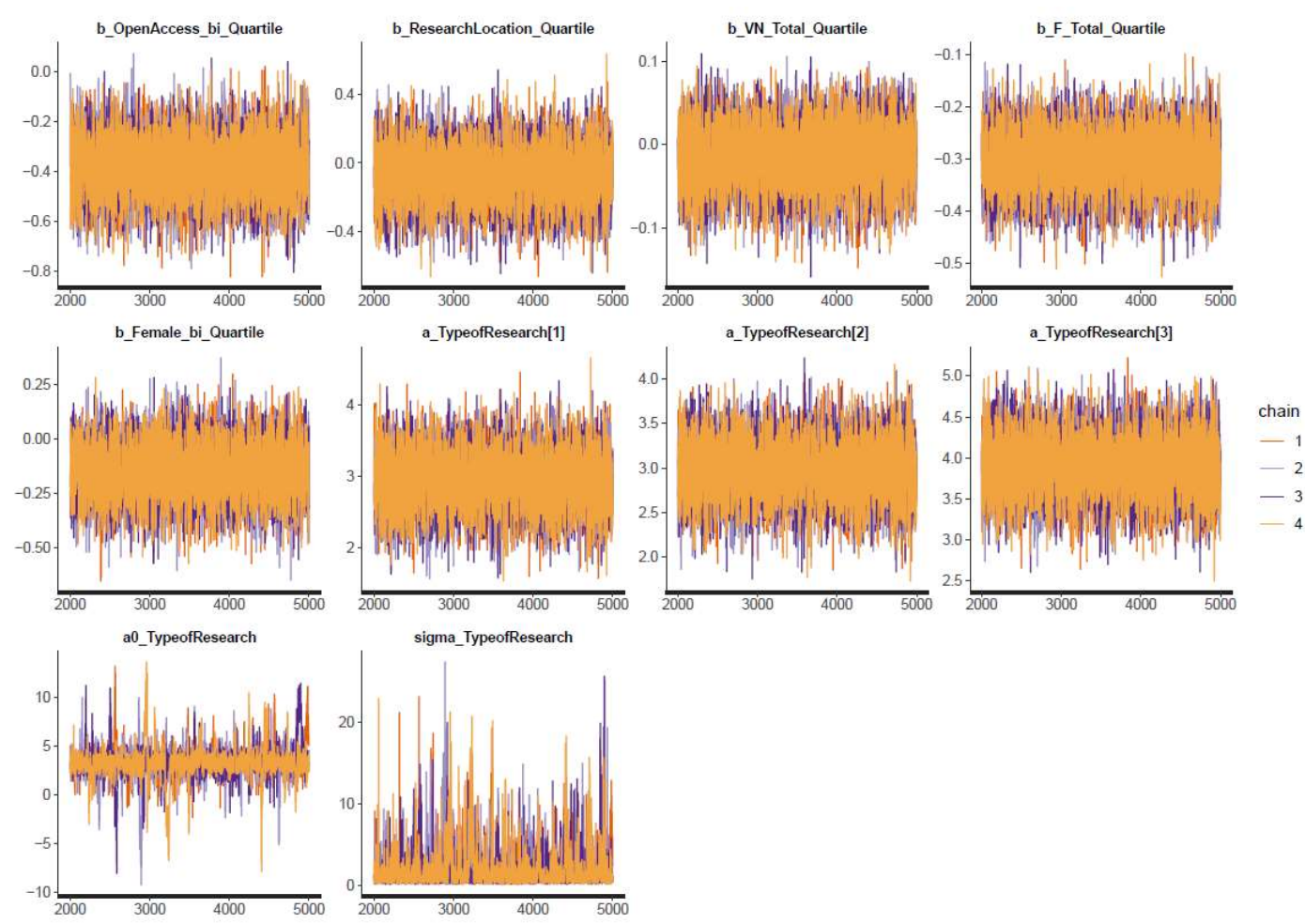

Figure 16. Visualization of MCMC chains for Model [2] Quartile

Figure 17 presented the distribution of coefficients for open access and research location. Firstly, the higher the quartile of an article, the more likely it is open access because the quartile's values run from 1 to 4 , with 1 is $\mathrm{Q} 1$, and 4 is $\mathrm{Q} 4(\beta=-0.38 ; \mathrm{SD}=0.12)$. The result suggested that Vietnamese development economics researchers have tried to make their article accessible to the public, especially in the higher quartile journals. Moreover, journals have been adopting new requirements regarding open access; thus, more papers are now open.

In terms of research location, papers with international data gained more attention from higher quartile journals $(\beta=-0.07 ; \mathrm{SD}=0.16)$, even though the effect was relatively small. In truth, as many high-quality journals often aim for novelty and universal issues, papers with domestic data appear to be too specific for these journals. 


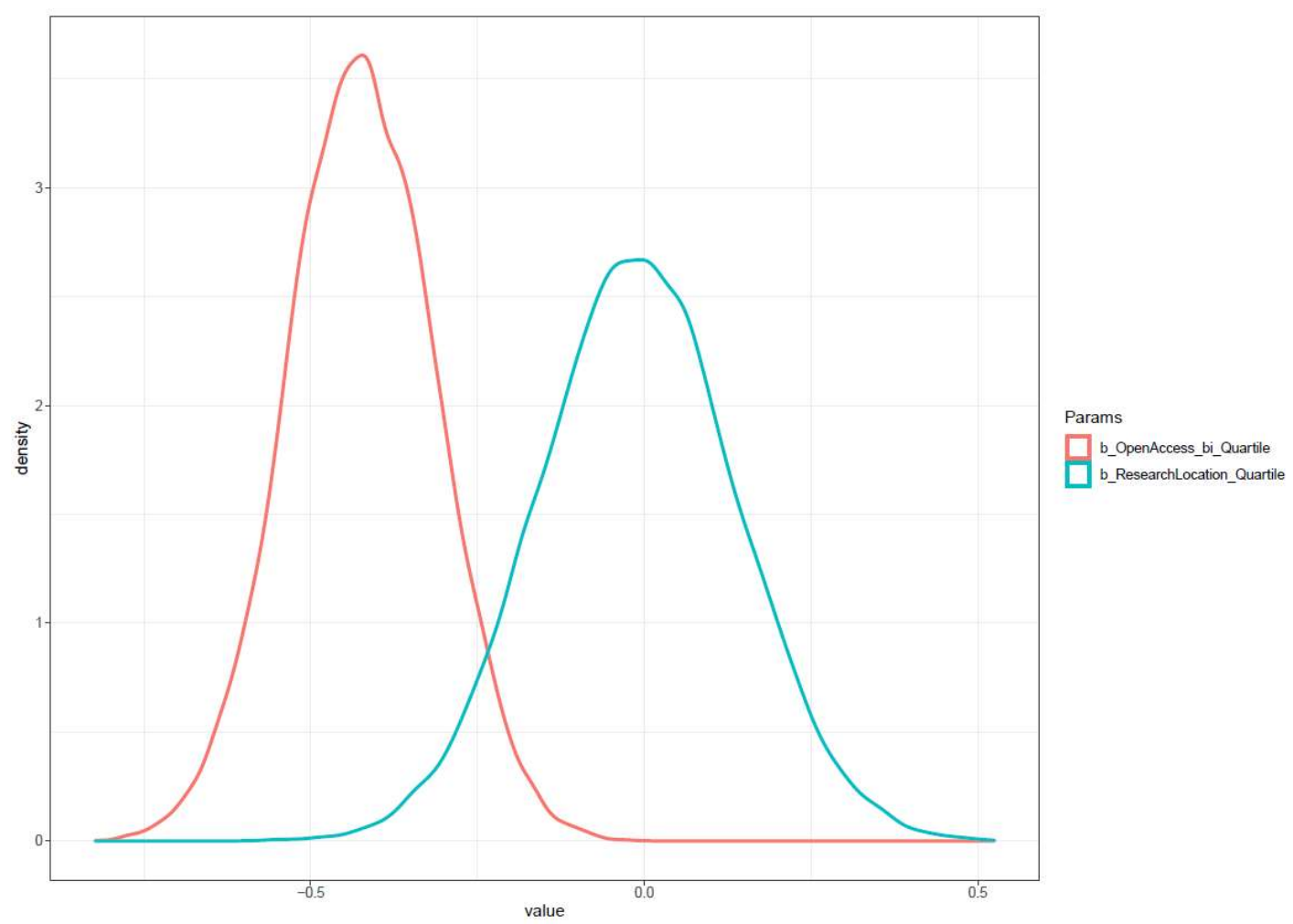

Figure 17. Distribution of coefficients for open access and research location for Model [2].

The number of Vietnamese authors in an article, the number of foreigners in an article, and the participation of female authors had negative associations with the quartile of the article. However, having more Vietnamese authors $(\beta=-0.02$; $\mathrm{SD}=0.04)$ appeared to decrease the quartile of an article, while having foreigners $(\beta=-0.30 ; \mathrm{SD}=0.06)$ significantly increased the quartile of an article. Regarding the participation of female authors, having a female author in a paper helped to improve the quartile of the paper $(\beta=-0.15 ; \mathrm{SD}=0.13)$.

International authors, who are more well-trained and familiar with scientific publishing, can improve the quality of the article. Moreover, as many Vietnamese researchers tend to publish with their supervisors, it can explain why having international authors in an article can improve its quartile. Meanwhile, female authors can provide a more balanced viewpoint, and their meticulous and careful manners can also make the article more attractive to higher quartile journals. 


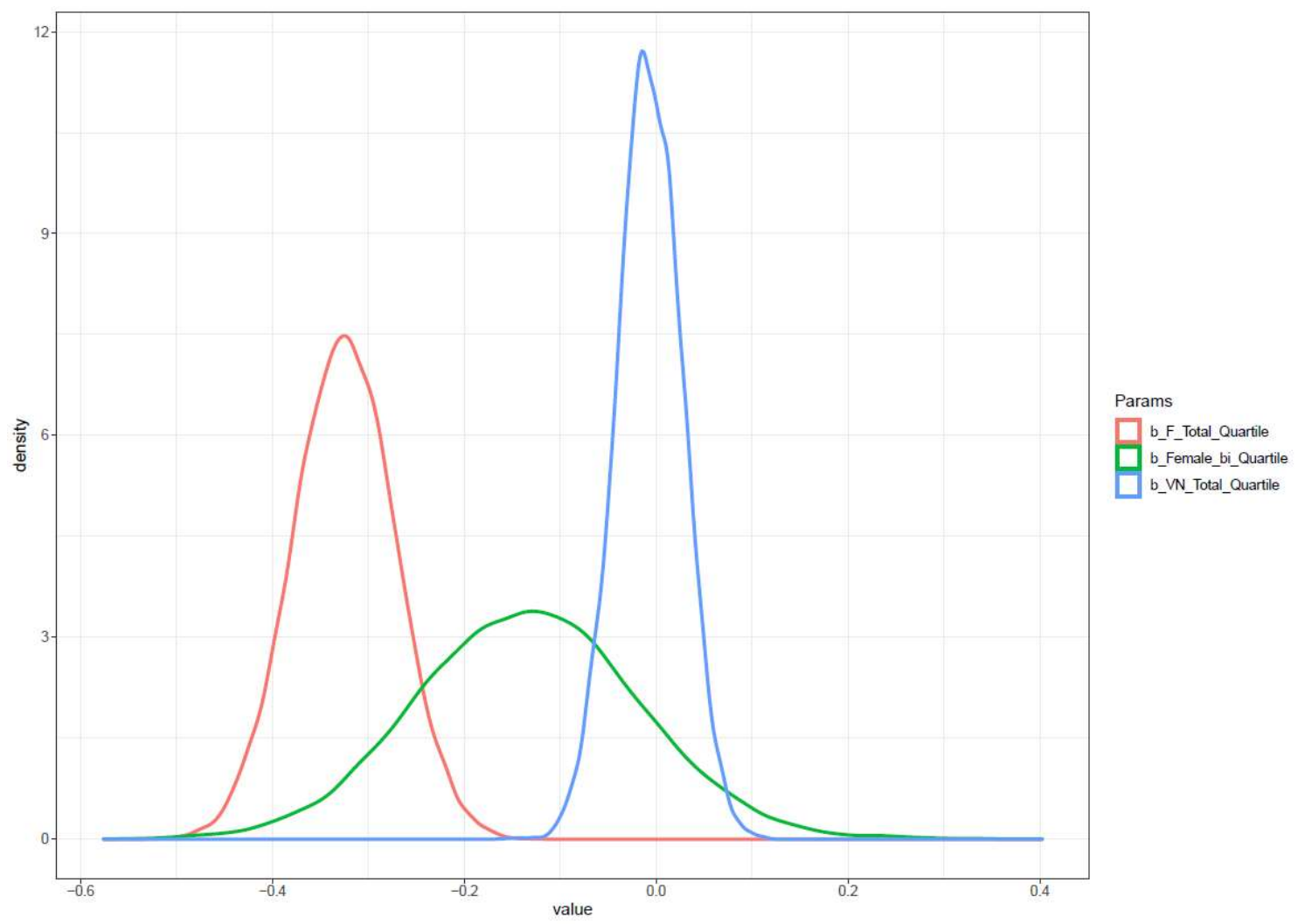

Figure 18. Distribution of coefficients of having women in the article, the total number of Vietnamese/foreign authors in the article for Model [2].

Finally, the type of research and its association with the quartile were examined. The result suggested no apparent difference between qualitative, quantitative, or theoretical papers.

\section{Model [3] Citation}

The Bayesian regression model was used to find the correlation between open access, research location, authors, type of research, and the adjusted citations of an article. The effective sample sizes, and Rhat's values of model [3] suggested good convergence. The loo test also showed that the model is good (see Table 8).

Table 8. Posterior estimation of model [3] Citation

\begin{tabular}{|l|l|l|l|l|}
\hline & Mean & SD & n_eff & Rhat \\
\hline b_OpenAccess_bi_AdjustCite & 0.03 & 4.30 & 5688 & 1 \\
\hline b_ResearchLocation_AdjustCite & 13.25 & 5.07 & 4651 & 1 \\
\hline b_VN_Total_AdjustCite & -2.27 & 1.50 & 1984 & 1 \\
\hline b_F_Total_AdjustCite & 15.94 & 2.24 & 8253 & 1 \\
\hline
\end{tabular}




\begin{tabular}{|l|l|l|l|l|}
\hline b_Female_bi_AdjustCite & -6.85 & 4.52 & 3494 & 1 \\
\hline a_TypeofResearch[1] & 41.87 & 14.09 & 2325 & 1 \\
\hline a_TypeofResearch[2] & 37.25 & 10.66 & 2666 & 1 \\
\hline a_TypeofResearch[3] & 27.49 & 10.57 & 5290 & 1 \\
\hline a0_TypeofResearch & 20.78 & 9.27 & 3782 & 1 \\
\hline sigma_TypeofResearch & 14.13 & 7.81 & 1271 & 1 \\
\hline $\begin{array}{l}\text { Monte Carlo SE of elpd_loo is } 0.0 . \\
\text { All Pareto } k \text { estimates are good }(k<0.5) .\end{array}$ & & \\
\hline
\end{tabular}

Figure 19 illustrated a good convergence of the MCMC chains for the model [3].
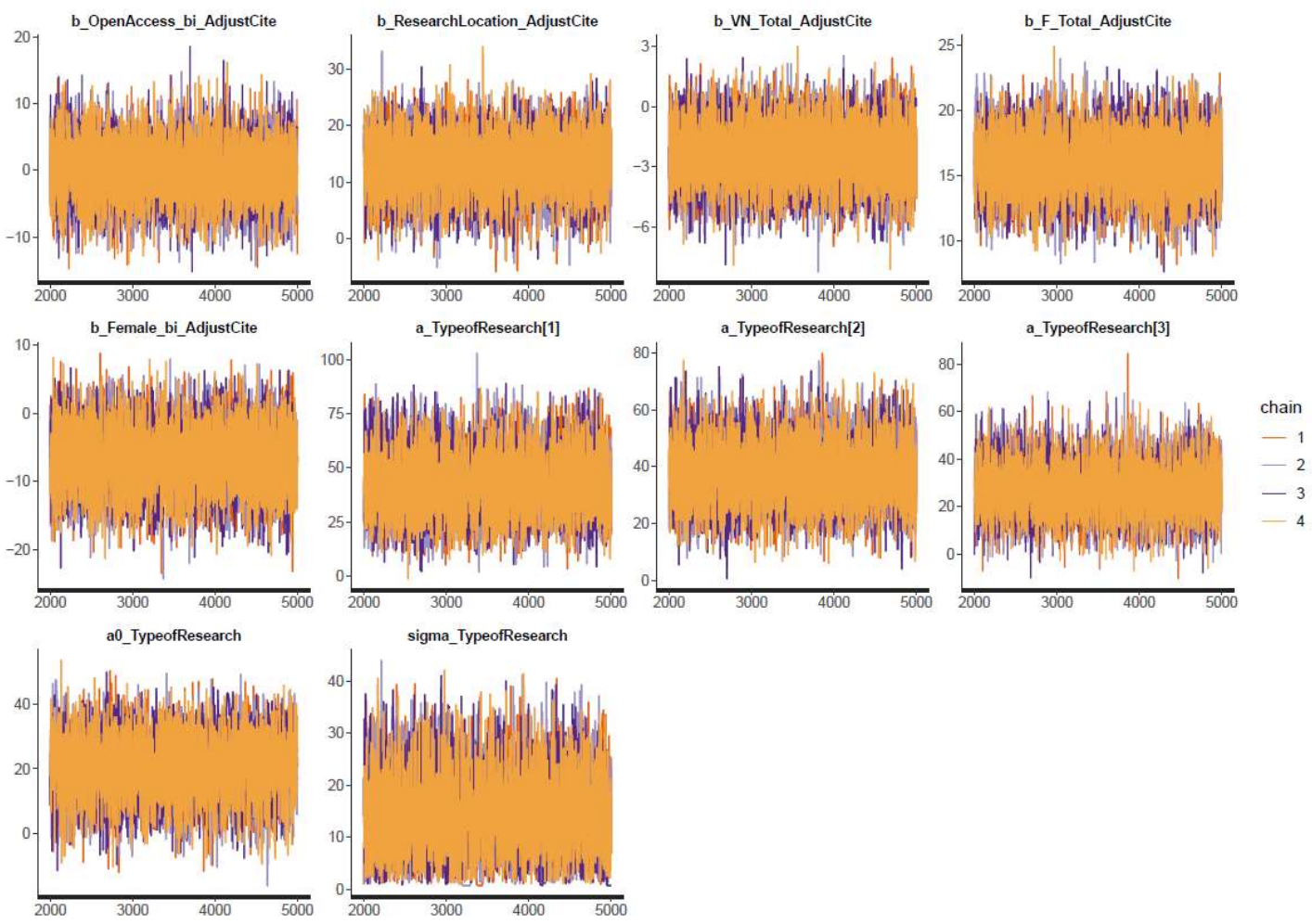

\section{Figure 19. Visualization of MCMC chains for Model [3] Citation}

The results in Figure 20 suggested that an open access article can slightly increase the citation $(\mathrm{B}=0.03 ; \mathrm{SD}=4.30)$. Open access articles are publicly available to readers; therefore, they are easier to access, especially for low-or-middle-income countries. Thus, the accessibility of open access articles seems to increase the chance of being cited. 
Moreover, papers used domestic data also had more chance of being cited ( $\mathrm{B}=13.25$; $\mathrm{SD}=5.07)$. Papers using data about Vietnam only were more focused than papers with international data, which usually compares across several countries.

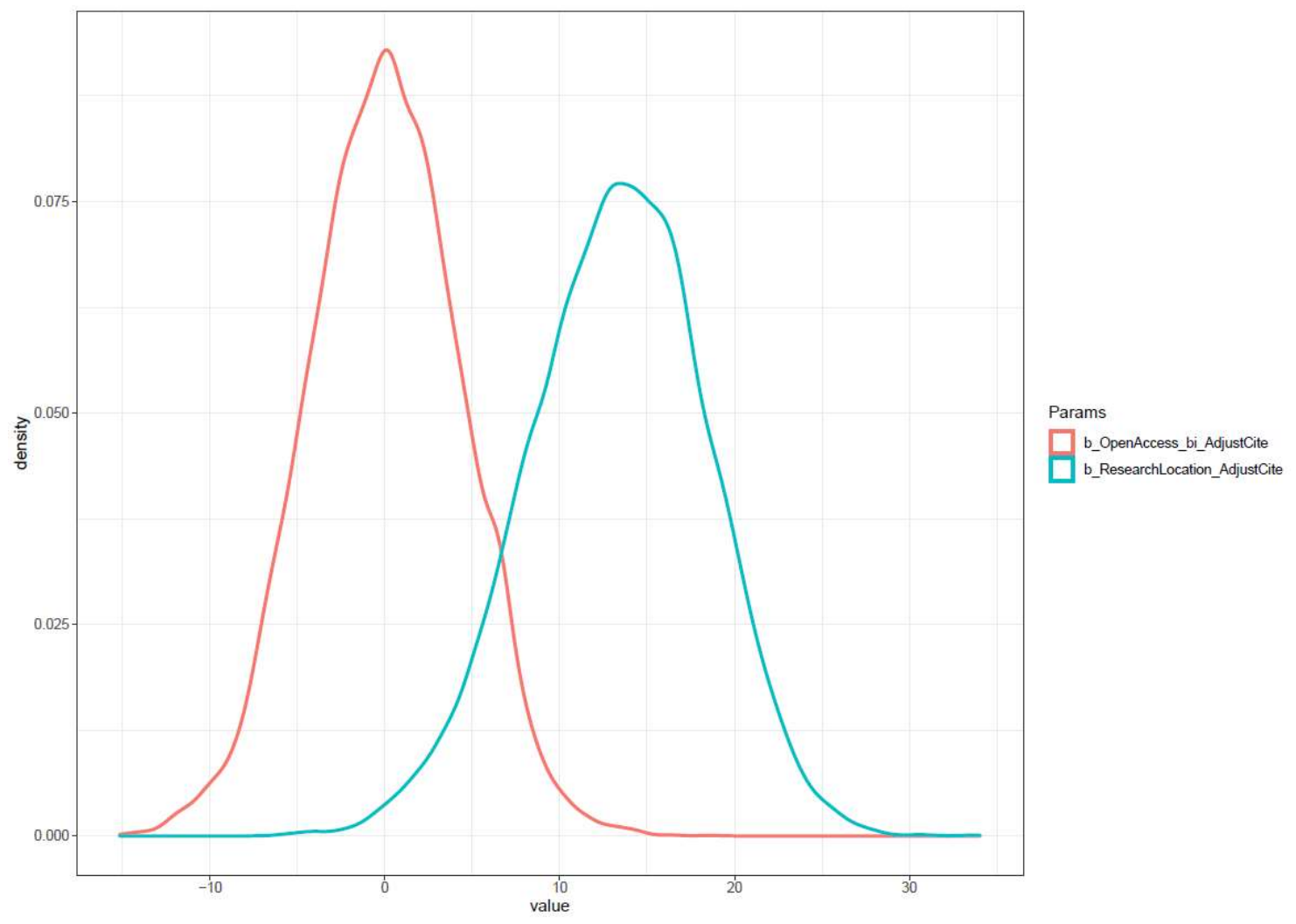

Figure 20. Distribution of coefficients for open access and research location for Model

[3].

The participation of female authors $(\beta=-6.85$; SD $=4.52)$ and the number of Vietnamese authors $(\beta=-2.27$; $\mathrm{SD}=1.50)$ in an article had negative correlations with the number of citations. In the case of the number of Vietnamese authors, as the total output and author network of development economics research in Vietnam is still low, the chance for an article to be cited is lower. On the contrary, having more foreign authors in an article significantly increased the chance of being cited $(\beta=15.94$; SD $=2.24)$. Possibly, foreign authors have better networks and connections so that they can easily introduce their works to their peers. Finally, the case of having female authors in an article is possibly the result of gender discrimination. 


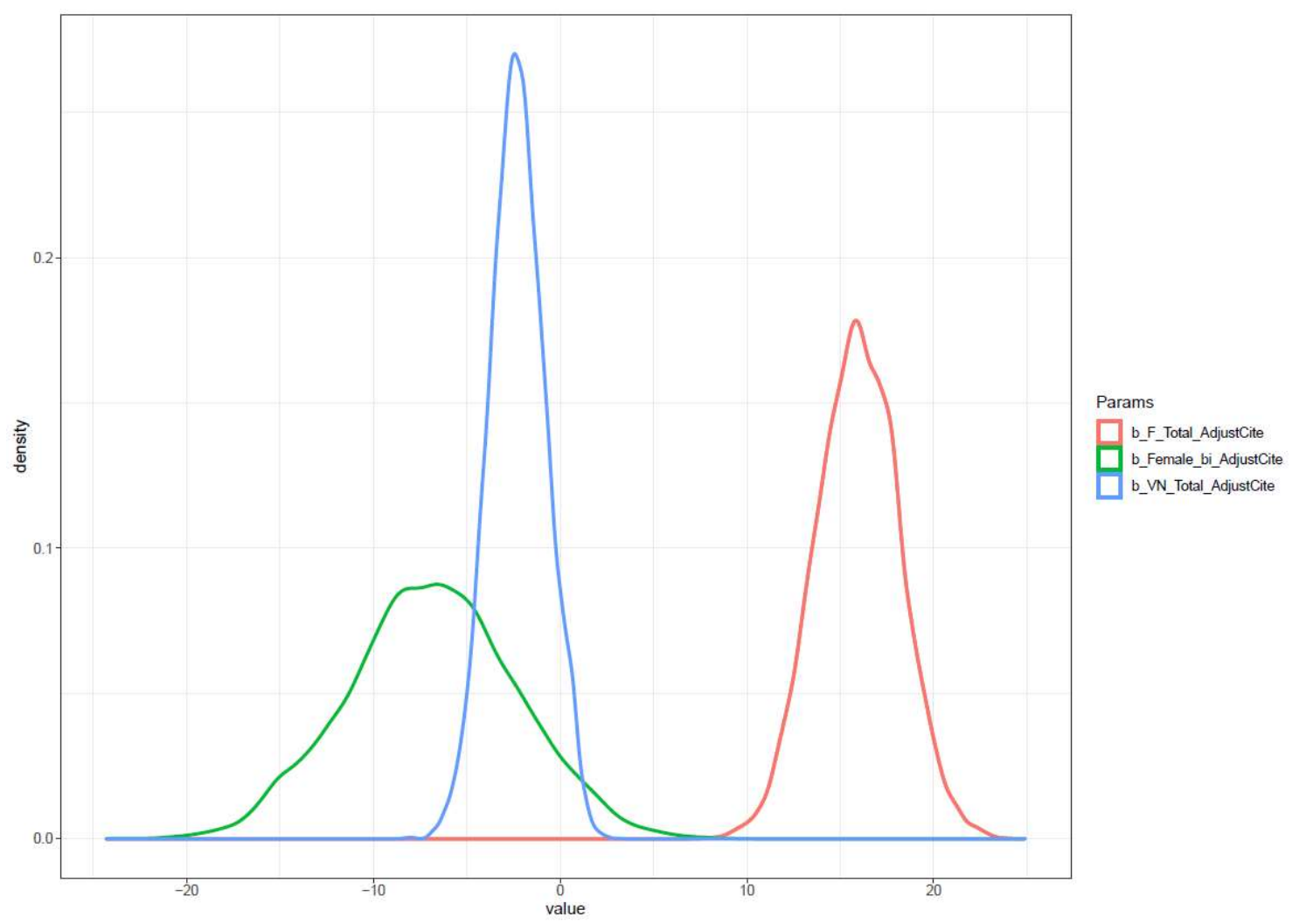

Figure 21. Distribution of coefficients of having women in the article, the total number of Vietnamese/foreign authors in the article for Model [2].

Finally, different types of research had no apparent effect on the chance of being cited. However, qualitative and quantitative papers are more likely to be cited than theoretical papers.

\subsection{Research Topics}

The field of development economics is a highly interdisciplinary field. The dendrogram in Figure 22 showed that 18 big fields in SSH have contributed to the literature of development economics in Vietnam. Indeed, Economics contributed the most articles, which was represented by the size of the ball. Following was Sociology, Agriculture, Environment/Sustainability Science, Education and Health Care. 


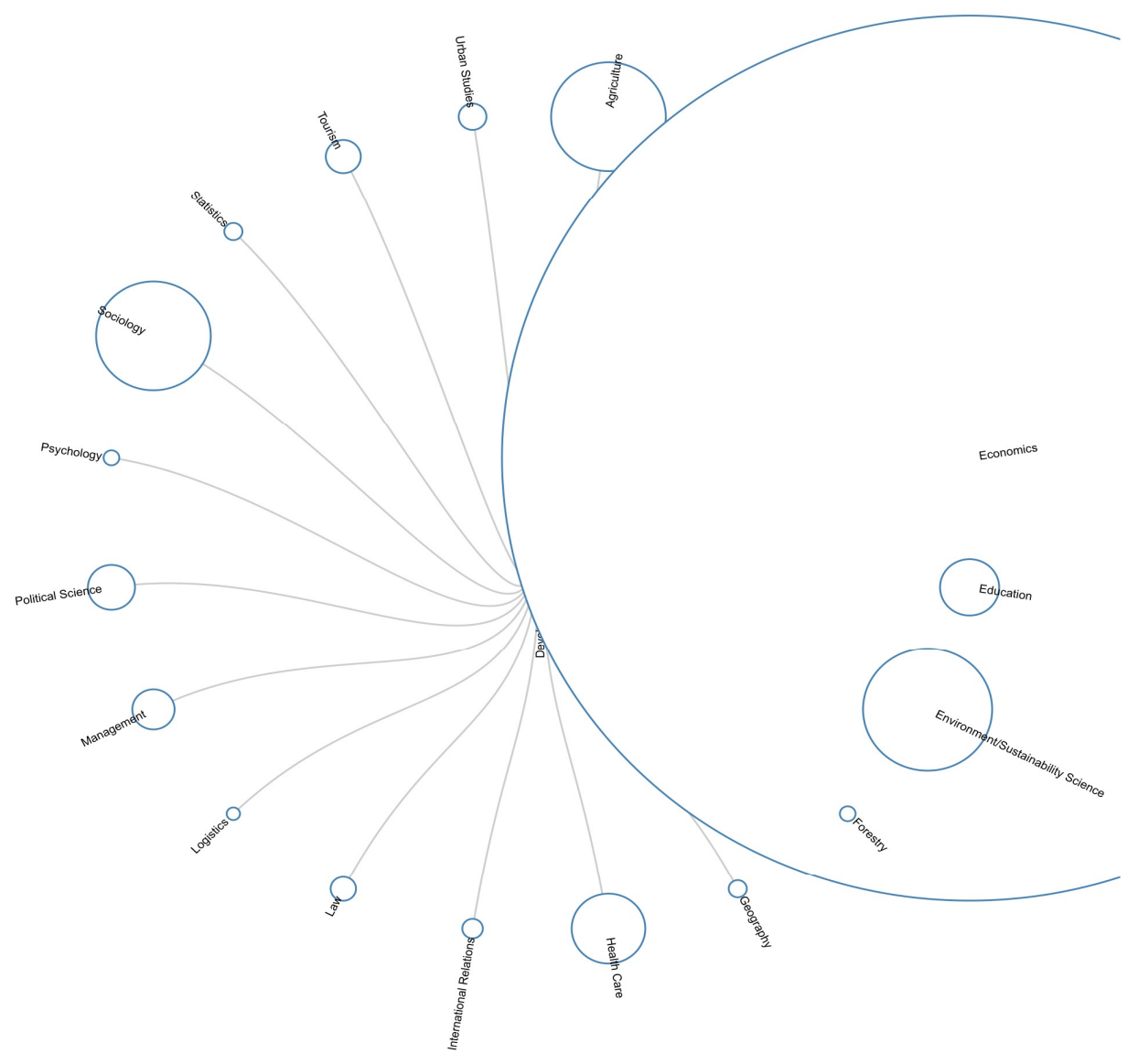

Figure 22. Dendrogram of development economics research in Vietnam in the 20082020 period.

Table 9 presented the number of articles according to each research topics in development economics research in Vietnam. It should be noted that one article can be assigned to multiple topics. Thus, the number represents which topics have been discussed or mentioned the most in the literature. Based on the number of articles on each topic, we can divide the research topics into three groups:

- The most discussed topics: Household Income, Poverty, Welfare, Institution.

- The heated topics: Inequality, Human Resource, Sustainability/Environment, FDI, Economic Growth, Finance, Export/Import, Labor Productivity. 
- The emerging topics: Natural Resources, Trade Liberalization, Entrepreneurship, Migration, Technology Development, Unemployment, Culture, Urbanization, Corruption, Industrialization 
Table 9. Number of articles by research topics

\begin{tabular}{|c|c|c|}
\hline Topic & Articles & Examples \\
\hline Household Income & 170 & (Few and Tran, 2010, Nguyen, 2014) \\
\hline Poverty & 142 & (Nguyen et al., 2015, Cuong, 2011) \\
\hline Welfare & 129 & $\begin{array}{l}\text { (Tran et al., 2018a, Coxhead et al., } \\
\text { 2012) }\end{array}$ \\
\hline Institution & 121 & $\begin{array}{l}\text { (Long and Pfau, 2009, Meschi et al., } \\
\text { 2016) }\end{array}$ \\
\hline Inequality & 96 & $\begin{array}{l}\text { (Nguyen and Simkin, 2017, Walder } \\
\text { and Nguyen, 2008) }\end{array}$ \\
\hline Human Resource & 77 & $\begin{array}{l}\text { (Mont and Cuong, 2011, Tran et al., } \\
\text { 2018b) }\end{array}$ \\
\hline Sustainability/Environment & 75 & $\begin{array}{l}\text { (Christensen and Bach, 2015, Nguyen } \\
\text { et al., 2017b) }\end{array}$ \\
\hline FDI & 70 & (Le, 2017, Anwar and Nguyen, 2011) \\
\hline Economic Growth & 62 & $\begin{array}{l}\text { (Nguyen et al., 2017a, Nguyen and } \\
\text { Pham, 2018) }\end{array}$ \\
\hline Finance & 61 & $\begin{array}{l}\text { (Dinh et al., 2019, Thu and Goto, } \\
\text { 2020) }\end{array}$ \\
\hline Export/Import & 59 & $\begin{array}{l}\text { (Hoang et al., 2020, Pham et al., } \\
\text { 2019a) }\end{array}$ \\
\hline Labor Productivity & 57 & $\begin{array}{l}\text { (Huy and Nonneman, 2016, Tung, } \\
\text { 2017) }\end{array}$ \\
\hline Natural Resources & 50 & $\begin{array}{l}\text { (Giesecke et al., 2013, Dinh et al., } \\
\text { 2017) }\end{array}$ \\
\hline Trade Liberalization & 47 & $\begin{array}{l}\text { (De Silva and Phuong, 2011, Kikuchi } \\
\text { et al., 2018) }\end{array}$ \\
\hline Entrepreneurship & 45 & $\begin{array}{l}\text { (Nguyen and Nordman, 2018, Van } \\
\text { Thang and Freeman, 2009) }\end{array}$ \\
\hline Migration & 38 & $\begin{array}{l}\text { (Cuong and Linh, 2018, Hoang et al., } \\
\text { 2012) }\end{array}$ \\
\hline Technology Development & 29 & $\begin{array}{l}\text { (Le and Pomfret, 2011, Vuong and } \\
\text { Nancy, 2014) }\end{array}$ \\
\hline Unemployment & 24 & $\begin{array}{l}\text { (Ho Dinh et al., 2020, Nguyen Hien } \\
\text { Thu et al., 2020) }\end{array}$ \\
\hline
\end{tabular}




\begin{tabular}{|l|l|l|}
\hline Culture & 12 & $\begin{array}{l}\text { (Nguyen et al., 2020b, Nguyen et al., } \\
2009)\end{array}$ \\
\hline Urbanization & 9 & $\begin{array}{l}\text { (Nguyen Ha and Nguyen Le, 2018, } \\
\text { Arouri et al., 2017) } \\
\text { (Anh et al., 2016, Thi Hoa, 2020) }\end{array}$ \\
\hline Corruption & 6 & (Pham et al., 2019b, Chau, 2018) \\
\hline Industrialization & 4 &
\end{tabular}

The most discussed topics had the highest number of articles on each topic. Figure 23 suggested that the topics are also highly connected. Indeed, poverty, household income, and welfare are interconnected issues that require coordinated efforts to solve effectively. Meanwhile, institutional issues touch upon almost every aspect of the economy. In general, the most discussed topics are fundamental issues for the development of Vietnam.

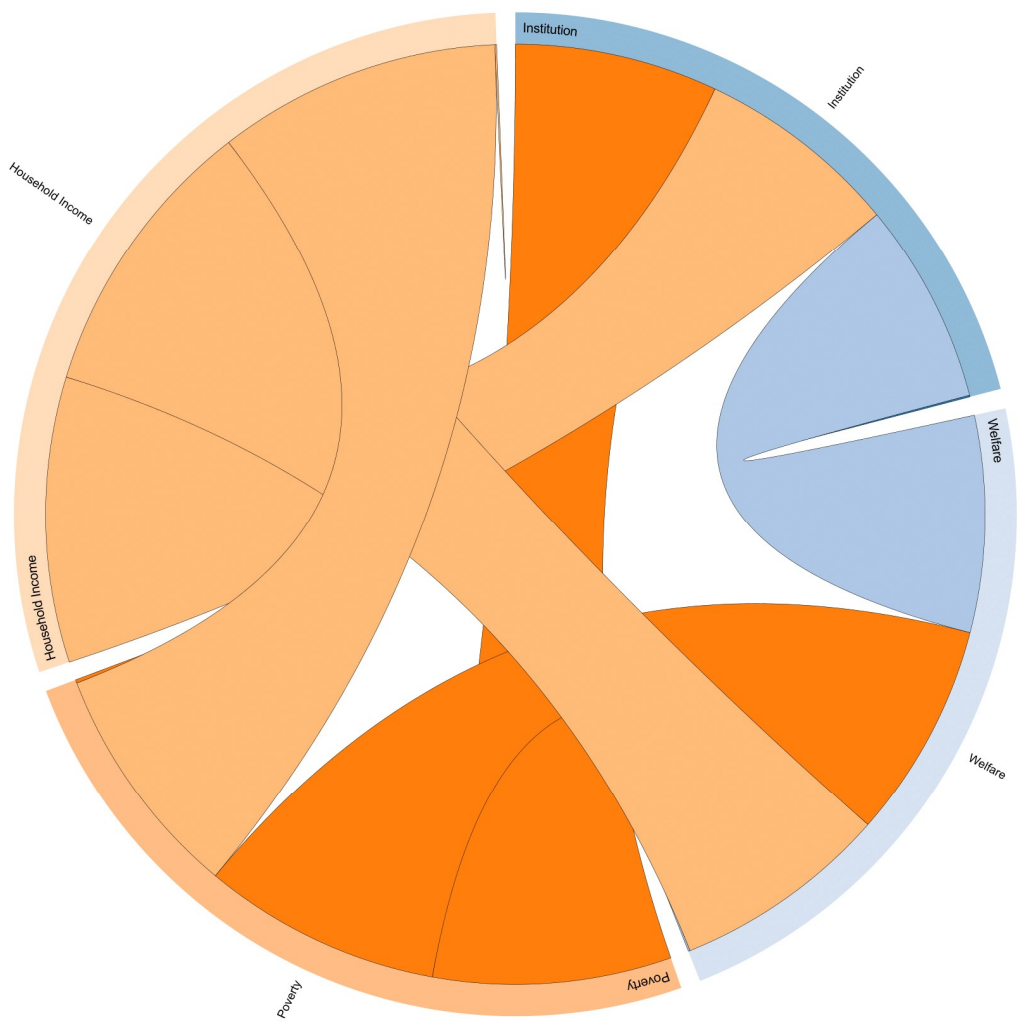

Figure 23. The connection among the most discussed topics.

The heated topics consisted of topics that are gaining more attention from the researchers in Vietnam (see Figure 24). The topics are not fundamental issues like the most 
discussed topics, but they are all extremely important for Vietnam's economic development. As Vietnam has become more active internationally, Foreign Direct Investment or Export/Import is necessary for the country to navigate its relationship with international friends. Meanwhile, economic development also comes with specific problems: Inequality, gender, and class, or Environmental/Sustainability issues. Finally, managing the country's Human Resources, Labor Productivity, Finance, and especially different aspects of Economics Growth is crucial for dealing with international relations and facing new problems.

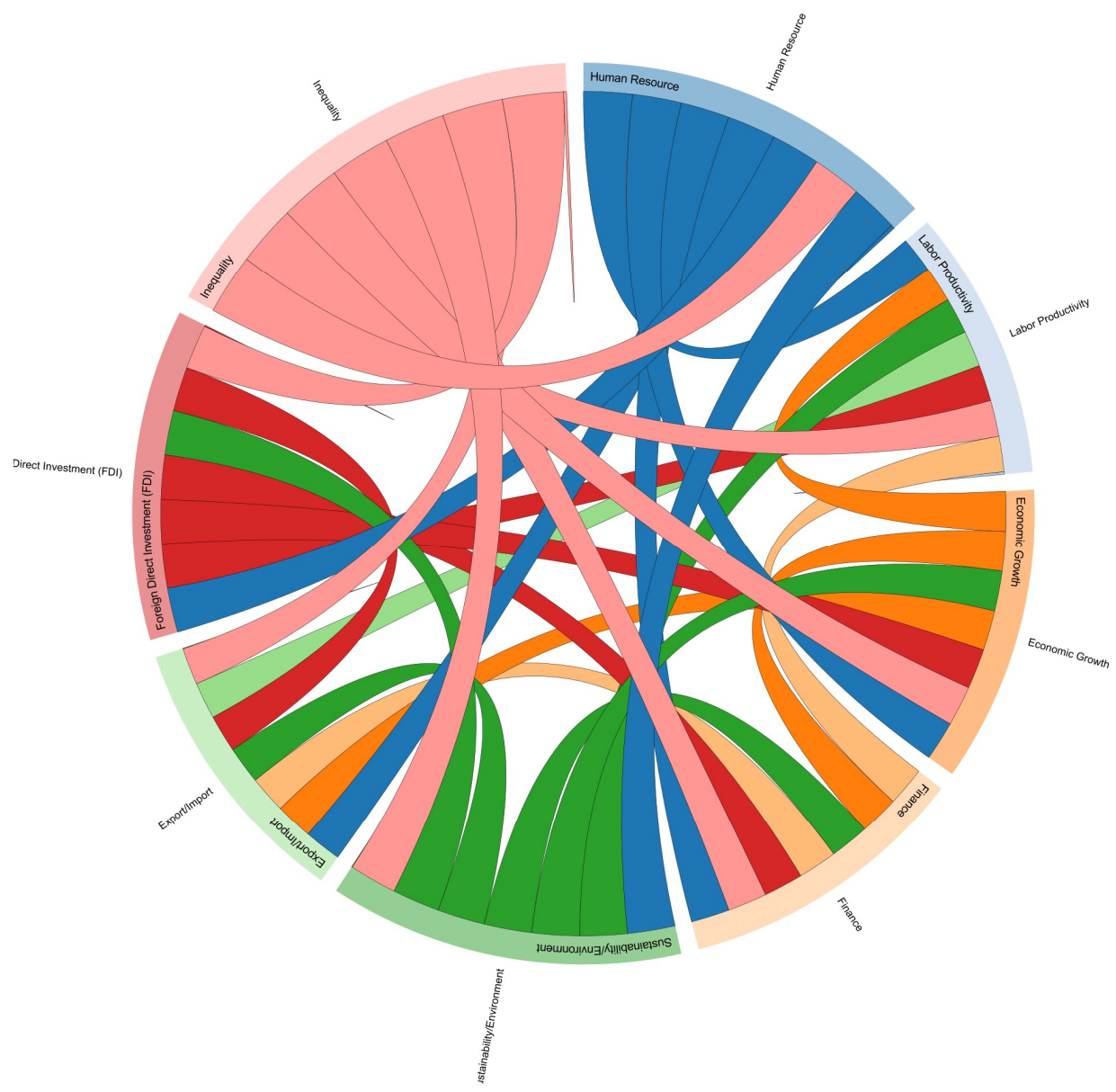

Figure 24. The connection between the heated topics.

Finally, emerging topics included both rising topics (Natural Resources) and underresearched topics (Urbanization). Indeed, some of the topics can belong to the heated topics. However, due to the nature of the interconnectivity of these topics, under 50 articles is a low number. Certain topics can be traced back to the heated and the most discussed topics. For instance, Natural Resources is an important aspect of Environmental/Sustainability. Unemployment and Migration can also be discussed in Labor Productivity or Human Resources. 


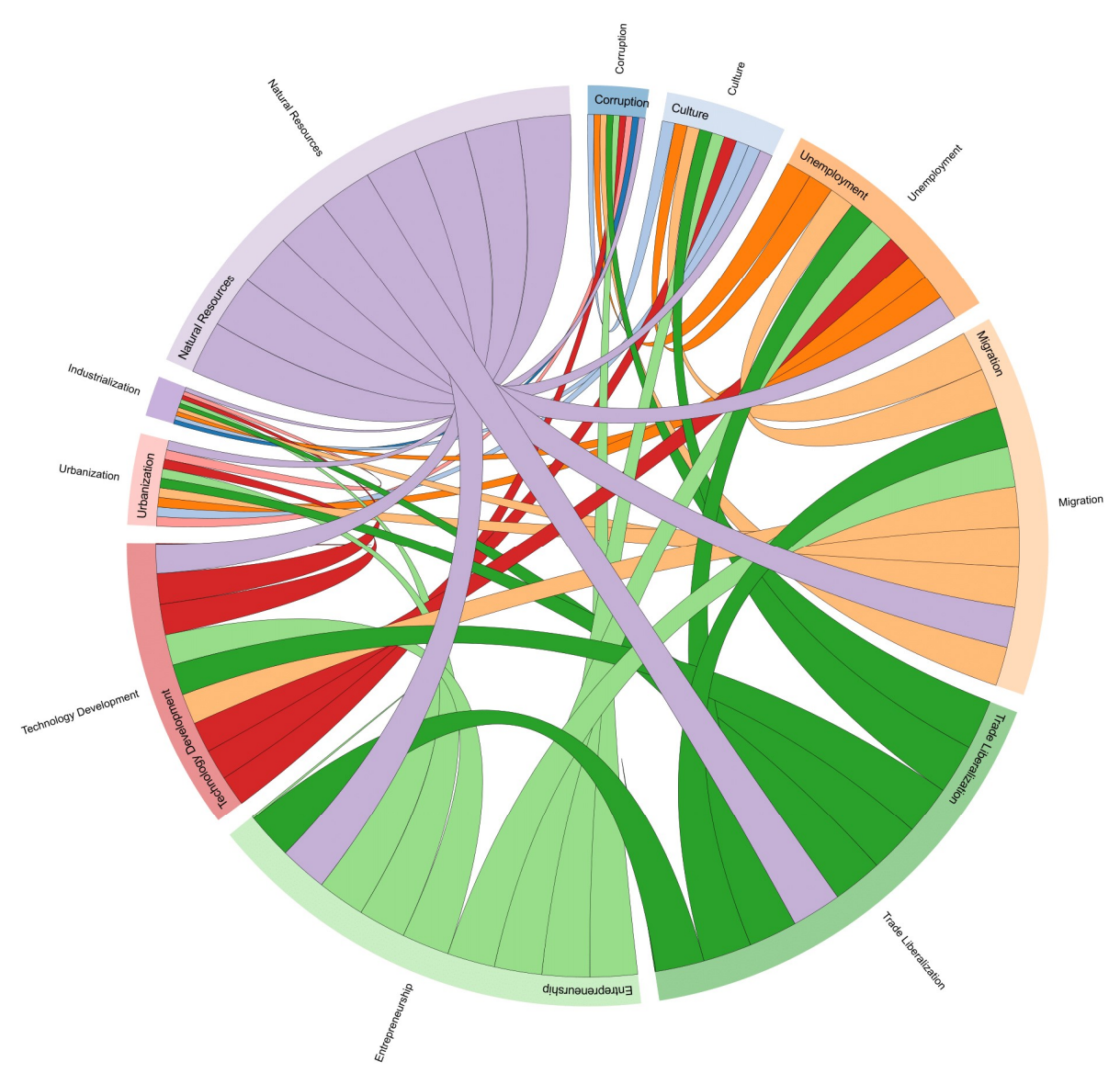

Figure 25. The connection between the emerging topics.

Meanwhile, Technological Development can be considered a uniquely $21^{\text {st }}$-century issue. How technology will contribute to the course of development, or how livelihood is going to change with technology are all new questions. The introduction of new variables such as the Internet, social media, or smartphone presents new and exciting challenges for researchers. In such a drastic change, cultural values are the anchor for a country like Vietnam. In the future, the study of culture and technology development can go hand-in-hand. The unenthusiastic engagement of development economic researchers to Urbanization, Corruption, and Industrialization issues in Vietnam is thought-provoking. The lack of studies regarding these issues is possibly due to the lack of data.

\section{CHAPTER 5}

\section{POLICY RECOMMENDATIONS AND CONCLUDING REMARKS}




\subsection{Major findings}

The study has four main findings. Firstly, following the development of the economy, and specifically science in Vietnam, the scientific productivity of development economics is also rising. Annually, the number of articles experienced a growth rate of around 23\%. In 2020, the total output was 101 articles as of August; thus, we expect an upward trend. Similarly, authors who contribute to the field is also rising, with an annual growth rate of $26 \%$. The rise of scientific publications resulted from the readiness of data, the ability to produce high-quality quantitative studies, the growth of international collaboration, and especially the dominance of the top $5 \%$ authors, who occupied $50.61 \%$ of the total output.

Secondly, Vietnamese development economics researchers have been able to publish frequently in high-quality journals in the field, i.e., Q1 and Q2 journals. In the top 15 journals, Q1 and Q2 journals dominated the list with 13 journals. Even in the top 5, two journals were highly respected in the field. Consequently, most of these journals are still closed access. However, international factors, such as international data or international authors, are correlated with the tendency to publish in open access journals. The results suggested that the adoption of open access will be considered more widely by scientists in the field.

Regarding the quality of publications, international factors were also associated with higher quartile and a higher chance of being cited. Understandably, as the scientific community in Vietnam is still rely on a small number of authors, international authors are not only important in the publishing process, but also post-publication process such as promotion. Open access journals also increase the chance for an article to be cited.

Finally, development economics research is a highly interdisciplinary field with a contribution from various big fields in social sciences and humanities. Traditional topics in development economics (poverty, household income, and welfare) were highly interrelated, and institutional discussion was entrenched in all mentioned topics. Analysis of emerging topics suggested that they reasonably reflected the heated concerns in Vietnam, including international trade and investment, sustainability issues such as environment, inequality, human resources. Emerging topics in development economics included natural resources, technology, and urbanization. However, most of the topics are under-researched, which might be due to the lack of data. Discussion on technological development is considered the topic of the 21 st century.

\subsection{Policy recommendations}


There are several recommendations for policymakers to manage the well of intellectual resources in the field of development economics. However, it should be noted that policymakers still need more evidence to arrive at the final conclusion. Firstly, as the upward trend will continue in the foreseeable future, maintaining quality and focus is crucial. Controlling the large volume of publications and navigating the good works will be big problems for policymakers and expert councils in the field. Thus, bibliometric databases and methods can help policymakers and expert councils to identify new topics or productive individuals or strong research teams. Moreover, they can also help to filter low-quality works that can potentially muddle the whole scene.

Moreover, approaching the open-access issue is also an important aspect that should not be overlooked. With movement like Plan S (Plan S, 2020), open access is inevitable in most developed scientific countries. However, open-access model can often be seen as low quality or a pay-to-publish scheme. Thus, policymakers should review the development of open access journals and provide useful guidelines and supports to manage the cost of science (Vuong, 2018).

The promotion of internal capacity is also vital for the field. Currently, Vietnamese authors rely on quantitative research and the availability of secondary data in Vietnam. Nevertheless, researchers should also focus on other forms as well. For instance, original dataset, innovative method, or new theory are all significant contributions to science that need more encouragement. Policymakers and university leaders can consider various long-term projects that require coherent collaboration in these aspects.

Finally, there are still many under-researched topics in development economics in Vietnam. Principal investigators, research team leaders, and researchers in the field can use the results of this study as an indication for future research direction.

\subsection{Concluding remarks}

The study is not without limitations (Vuong, 2020). Firstly, the overview of the development economics research in Vietnam is provided through descriptive statistics. While these statistics are easy to understand, they may not represent the whole picture and need more sophistication. Moreover, simple Bayesian regression models are used to explore associations between factors and the tendency for open access, and the quality of articles. Future studies can use more complex approaches to explore these associations. In terms of quality, the study used two standard metrics: quartile and citation, as indicators of quality. However, there are different 
metrics such as journal impact factors and they can offer different insights. Finally, as a master thesis, the recommendations may need further perspectives from senior figures.

The thesis has successfully provided snapshots of the growth of development economics research in Vietnam. By using bibliometric methods, the trends of development, the factors influencing the quality of articles, and open access decisions of researchers, hot and under-researched topics are identified and discussed. To the best of my knowledge, this is the first work that produce such ambitious. Future studies should use the results in this study as a point of reference. 


\section{REFERENCES}

ADAMS, J., PENDLEBURY, D., ROGERS, G. \& SZOMSZOR, M. 2019. Global Research Report - South and East Asia. Institute for Scientific Information.

ANH, N. N., MINH, N. N. \& TRAN-NAM, B. 2016. Corruption and economic growth, with a focus on Vietnam. Crime, Law and Social Change, 65, 307-324.

ANWAR, S. \& NGUYEN, L. P. 2010. Foreign direct investment and economic growth in Vietnam. Asia Pacific Business Review, 16, 183-202.

ANWAR, S. \& NGUYEN, L. P. 2011. Foreign direct investment and trade: The case of Vietnam. Research in International Business and Finance, 25, 39-52.

AROURI, M., BEN YOUSSEF, A. \& NGUYEN, C. 2017. Does urbanization reduce rural poverty? Evidence from Vietnam. Economic Modelling, 60, 253-270.

AROURI, M., NGUYEN, C. \& YOUSSEF, A. B. 2015. Natural Disasters, Household Welfare, and Resilience: Evidence from Rural Vietnam. World Development, 70, 59-77.

BERENBAUM, M. R. 2019. Impact factor impacts on early-career scientist careers. Proceedings of the National Academy of Sciences, 116, 16659-16662.

CHAU, L. M. 2018. Actively cautious: Industrialization and rural livelihood choices in contemporary northern Vietnam. South East Asia Research, 26, 21-37.

CHIMHOWU, A. O., HULME, D. \& MUNRO, L. T. 2019. The 'New' national development planning and global development goals: Processes and partnerships. World Development, $120,76-89$.

CHRISTENSEN, D. \& BACH, L. T. 2015. A Danish-Vietnamese partnership for business and technology development in solid waste management. Resources, Conservation and Recycling, 105, 123-133.

CLEMENS, M. A., ÖZDEN, Ç. \& RAPOPORT, H. 2014. Migration and Development Research is Moving Far Beyond Remittances. World Development, 64, 121-124.

COLMAN, D. \& NIXSON, F. I. 1986. Economics of change in less developed countries, Rowman \& Littlefield.

COXHEAD, I., LINH, V. H. \& TAM, L. D. 2012. Global market shocks and poverty in Vietnam: the case of rice. Agricultural Economics, 43, 575-592.

CUONG, N. V. 2011. Can Vietnam achieve the millennium development goal on poverty reduction in high inflation and economic stagnation? Developing Economies, 49, 297 320.

CUONG, N. V. \& LINH, V. H. 2018. The Impact of Migration and Remittances on Household Welfare: Evidence from Vietnam. Journal of International Migration and Integration, 19, 945-963.

DE SILVA, S. S. \& PHUONG, N. T. 2011. Striped catfish farming in the Mekong Delta, Vietnam: a tumultuous path to a global success. Reviews in Aquaculture, 3, 45-73.

DIAS, C. S. L., RODRIGUES, R. G. \& FERREIRA, J. J. 2019a. Agricultural entrepreneurship: Going back to the basics. Journal of Rural Studies, 70, 125-138.

DIAS, C. S. L., RODRIGUES, R. G. \& FERREIRA, J. J. 2019b. What's new in the research on agricultural entrepreneurship? Journal of Rural Studies, 65, 99-115.

DINH, H. H., NGUYEN, T. T., HOANG, V.-N. \& WILSON, C. 2017. Economic incentive and factors affecting tree planting of rural households: Evidence from the Central Highlands of Vietnam. Journal of Forest Economics, 29, 14-24.

DINH, T. T.-H., VO, D. H., THE VO, A. \& NGUYEN, T. C. 2019. Foreign Direct Investment and Economic Growth in the Short Run and Long Run: Empirical Evidence from Developing Countries. Journal of Risk and Financial Management, 12, 176. 
ELLEGAARD, O. \& WALLIN, J. A. 2015. The bibliometric analysis of scholarly production: How great is the impact? Scientometrics, 105, 1809-1831.

ELliotT, J. H., TURNER, T., ClAVISI, O., THOMAS, J., HIGGINS, J. P. T., MAVERGAMES, C. \& GRUEN, R. L. 2014. Living Systematic Reviews: An Emerging Opportunity to Narrow the Evidence-Practice Gap. PLOS Medicine, 11, e1001603.

EXTANCE, A. 2018. How AI technology can tame the scientific literature. Nature, 561, 273 274.

FEW, R. \& TRAN, P. G. 2010. Climatic hazards, health risk and response in Vietnam: Case studies on social dimensions of vulnerability. Global Environmental Change, 20, 529538.

GIESECKE, J. A., TRAN, N. H., CORONG, E. L. \& JAFFEE, S. 2013. Rice Land Designation Policy in Vietnam and the Implications of Policy Reform for Food Security and Economic Welfare. The Journal of Development Studies, 49, 1202-1218.

GILLIS, M., PERKINS, D. H., ROEMER, M. \& SNODGRASS, D. R. 1992. Economics of development, WW Norton \& Company, Inc.

HALLINGER, P. \& NGUYEN, V.-T. 2020. Mapping the Landscape and Structure of Research on Education for Sustainable Development: A Bibliometric Review. Sustainability, 12, 1947.

HAYAMI, Y., HAYAMI, Y., GODO, Y. \& GŌDO, Y. 2005. Development economics: From the poverty to the wealth of nations, Oxford University Press.

HEAVEN, D. 2018. AI peer reviewers unleashed to ease publishing grind. Nature, 563, 609610.

HIEN, P. D. 2010. A comparative study of research capabilities of East Asian countries and implications for Vietnam. Higher Education, 60, 615-625.

HO DINH, B., NGUYEN PHUC, H., BUI, T. \& NGUYEN, H. 2020. Declining Protection for Vietnamese Agriculture under Trade Liberalization: Evidence from an Input-Output Analysis. Economies, 8, 43.

HO, L. \& GOETHALS, P. 2020. Research hotspots and current challenges of lakes and reservoirs: a bibliometric analysis. Scientometrics, 124, 603-631.

HO, M.-T., VUONG, T.-T., PHAM, T.-H., LUONG, A.-P., NGUYEN, T.-N. \& VUONG, Q.H. 2020. The Internal Capability of Vietnam Social Sciences and Humanities: A Perspective from the 2008-2019 Dataset. Publications, 8, 32.

HO, T., NGUYEN, H., VUONG, T., DAM, Q., PHAM, H. \& VUONG, Q. 2017a. Exploring Vietnamese co-authorship patterns in social sciences with basic network measures of 2008-2017 Scopus data. F1000Research, 6.

HO, T. M., NGUYEN, H. K. T., VUONG, T.-T. \& VUONG, Q.-H. 2017b. On the Sustainability of Co-Authoring Behaviors in Vietnamese Social Sciences: A Preliminary Analysis of Network Data. Sustainability, 9, 2142.

HOANG, L. A., YEOH, B. S. A. \& WATTIE, A. M. 2012. Transnational labour migration and the politics of care in the Southeast Asian family. Geoforum, 43, 733-740.

HOANG, N. T. T., TRUONG, H. Q. \& VAN DONG, C. 2020. Determinants of Trade Between Taiwan and ASEAN Countries: A PPML Estimator Approach. SAGE Open, 10, 2158244020919516.

HUY, H. T. \& NONNEMAN, W. 2016. Economic effects of labor migration on agricultural production of farm households in the Mekong River Delta region of Vietnam. Asian and Pacific Migration Journal, 25, 3-21.

INGHAM, B. 1993. The meaning of development: Interactions between "new" and "old" ideas. World development, 21, 1803-1821. 
IOANNIDIS, J. P. A., KLAVANS, R. \& BOYACK, K. W. 2018. Thousands of scientists publish a paper every five days. Nature, 561, 167-169.

KH.V. 2018. Năng suất lao động tăng cải thiện chất lượng tăng trưởng kinh tế 2018 [Online]. Lao Động Online. Available: https://laodong.vn/kinh-te/nang-suat-lao-dong-tang-caithien-chat-luong-tang-truong-kinh-te-2018-649319.1do [Accessed October 13 2020].

KHAI, H. V. 2014. The Economic Benefits of Surface Water Quality Improvements: A Case of Channel in the Mekong Delta, Vietnam. The International Journal of Environmental Sustainability, 9, 71-83.

KIKUCHI, T., YANAGIDA, K. \& VO, H. 2018. The effects of Mega-Regional Trade Agreements on Vietnam. Journal of Asian Economics, 55, 4-19.

KUMAR, R. R., STAUVERMANN, P. J. \& PATEL, A. 2016. Exploring the link between research and economic growth: an empirical study of China and USA. Quality \& Quantity, 50, 1073-1091.

LA, V.-P., PHAM, T.-H., HO, M.-T., NGUYEN, M.-H., P. NGUYEN, K.-L., VUONG, T.-T., NGUYEN, H.-K. T., TRAN, T., KHUC, Q., HO, M.-T. \& VUONG, Q.-H. 2020. Policy Response, Social Media and Science Journalism for the Sustainability of the Public Health System Amid the COVID-19 Outbreak: The Vietnam Lessons. Sustainability, $12,2931$.

LANDHUIS, E. 2016. Scientific literature: Information overload. Nature, 535, 457-458.

LANJOUW, J. O. \& COCKBURN, I. M. 2001. New Pills for Poor People? Empirical Evidence after GATT. World Development, 29, 265-289.

LE, H. Q. \& POMFRET, R. 2011. Technology spillovers from foreign direct investment in Vietnam: horizontal or vertical spillovers? Journal of the Asia Pacific Economy, 16, 183-201.

LE, H. T. T., DAO, Q. T. M., PHAM, V.-C. \& TRAN, D. T. 2019. Global trend of open innovation research: A bibliometric analysis. Cogent Business \& Management, 6.

LE, T.-H. 2017. Does economic distance affect the flows of trade and foreign direct investment? Evidence from Vietnam. Cogent Economics \& Finance, 5, 1403108.

LONG, G. T. \& PFAU, W. D. 2009. Ageing, Poverty and the Role of a Social Pension in Vietnam. Development and Change, 40, 333-360.

LÓPEZ-FERNÁNDEZ, M. C., SERRANO-BEDIA, A. M. \& PÉREZ-PÉREZ, M. 2016. Entrepreneurship and Family Firm Research: A Bibliometric Analysis of An Emerging Field. 54, 622-639.

MADRUEÑO, R. \& TEZANOS, S. 2018. The contemporary development discourse: Analysing the influence of development studies' journals. World Development, 109, 334-345.

MANH, H. D. 2015. Scientific publications in Vietnam as seen from Scopus during 19962013. Scientometrics, 105, 83-95.

MCKENZIE, D. \& PAFFHAUSEN, A. L. 2017. What Is Considered Development Economics? Commonalities and Differences in University Courses around the Developing World. The World Bank Economic Review, 31, 595-610.

MCLEOD, S. 2007. Maslow's hierarchy of needs. Simply psychology, 1, 1-8.

MESCHI, P.-X., PHAN, T. T. \& WASSMER, U. 2016. Transactional and institutional alignment of entry modes in transition economies. A survival analysis of joint ventures and wholly owned subsidiaries in Vietnam. International Business Review, 25, 946959.

MITRA, S., PALMER, M. \& VUONG, V. 2020. Development and interdisciplinarity: A citation analysis. World Development, 135, 105076.

MONT, D. \& CUONG, N. V. 2011. Disability and Poverty in Vietnam. The World Bank Economic Review, 25, 323-359. 
NGUYEN, C. H. \& NORDMAN, C. J. 2018. Household Entrepreneurship and Social Networks: Panel Data Evidence from Vietnam. The Journal of Development Studies, 54, 594-618.

NGUYEN, C. V. \& PHAM, N. M. 2018. Economic growth, inequality, and poverty in Vietnam. Asian-Pacific Economic Literature, 32, 45-58.

NGUYEN, C. V. \& TRAN, A. 2014. Poverty identification: practice and policy implications in Vietnam. Asian-Pacific Economic Literature, 28, 116-136.

NGUYEN, D. 2019. Mapping knowledge domains of non-biomedical modalities: A large-scale co-word analysis of literature 1987-2017. Social Science \& Medicine, 233, 1-12.

NGUYEN, D. T. H., SUN, S. \& ANWAR, S. 2017a. A long-run and short-run analysis of the macroeconomic interrelationships in Vietnam. Economic Analysis and Policy, 54, $15-$ 25.

NGUYEN HA, M. \& NGUYEN LE, D. 2018. The relationship between urbanization and economic growth: An empirical study on ASEAN countries. International Journal of Social Economics, 45, 316-339.

NGUYEN, H. H. 2014. Grassroots Democracy and Inequality Reduction in Rural Vietnam: The Case of Thái Bình in 1997 and Now. Asian Journal of Political Science, 22, 71-92.

NGUYEN HIEN THU, T., GIANG LONG, T. \& PHAM TOAN, N. 2020. Impacts of higher tobacco tax on output and employment in Vietnam. Journal of Economics and Development, 22, 167-182.

NGUYEN, M.-H., HO, M.-T., LA, V.-P., NGUYEN, Q.-Y. T., HO, M.-T., VUONG, T.-T., LE, T.-T., NGUYEN, M.-C. \& VUONG, Q.-H. 2020a. A Scientometric Study on Depression among University Students in East Asia: Research and System Insufficiencies? Sustainability, 12, 1498.

NGUYEN, T. A., GILLEN, J. \& RIGG, J. 2020b. Economic transition without agrarian transformation: the pivotal place of smallholder rice farming in Vietnam's modernisation. Journal of Rural Studies, 74, 86-95.

NGUYEN, T. A., VU, D. A., VAN VU, P., NGUYEN, T. N., PHAM, T. M., NGUYEN, H. T. T., TRINH LE, H., NGUYEN, T. V., HOANG, L. K., VU, T. D., NGUYEN, T. S., LUONG, T. T., TRINH, N. P. \& HENS, L. 2017b. Human ecological effects of tropical storms in the coastal area of Ky Anh (Ha Tinh, Vietnam). Environment, Development and Sustainability, 19, 745-767.

NGUYEN, T. Q. T. \& SIMKIN, K. 2017. Gender discrimination in Vietnam: the role of personal face. Journal of Gender Studies, 26, 609-617.

NGUYEN, T. V., BRYANT, S. E., ROSE, J., TSENG, C.-H. \& KAPASUWAN, S. 2009. Cultural values, market institutions, and entrepreneurship potential: A comparative study of the United States, Taiwan, and Vietnam. Journal of Developmental Entrepreneurship, 14, 21-37.

NGUYEN, T. V., HO-LE, T. P. \& LE, U. V. 2017c. International collaboration in scientific research in Vietnam: an analysis of patterns and impact. Scientometrics, 110, 10351051.

NGUYEN, T. V., LE, C. Q., TRAN, B. T. \& BRYANT, S. E. 2015. Citizen Participation in City Governance: Experiences From Vietnam. Public Administration and Development, 35, 34-45.

NGUYEN, T. V. \& PHAM, L. T. 2011. Scientific output and its relationship to knowledge economy: an analysis of ASEAN countries. Scientometrics, 89, 107-117.

ODHIAMBO NICHOLAS, M. \& NTENGA, L. 2016. Research publications and economic growth in South Africa: an empirical investigation. International Journal of Social Economics, 43, 662-675. 
OLCZYK, M. 2016. A systematic retrieval of international competitiveness literature: a bibliometric study. Eurasian Economic Review, 6, 429-457.

PALOMO, J., FIGUEROA-DOMECQ, C. \& LAGUNA, P. 2017. Women, peace and security state-of-art: a bibliometric analysis in social sciences based on SCOPUS database. Scientometrics, 113, 123-148.

PHAM, A. D., PHAM, H. \& LY, K. C. 2019a. Double Taxation Treaties as a Catalyst for Trade Developments: A Comparative Study of Vietnam's Relations with ASEAN and EU Member States. Journal of Risk and Financial Management, 12, 172.

PHAM, K. T. H., NGUYEN, L. H., VUONG, Q.-H., HO, M.-T., VUONG, T.-T., NGUYEN, H.-K. T., VU, G. T., NGUYEN, H. L. T., TRAN, B. X., LATKIN, C. A., HO, C. S. H. \& HO, R. C. M. 2019b. Health Inequality between Migrant and Non-Migrant Workers in an Industrial Zone of Vietnam. International Journal of Environmental Research and Public Health, 16, 1502.

PLAN S. 2020. Plan S Making full and immediate Open Access a reality [Online]. Available: https://www.coalition-s.org/ [Accessed October 28 2020].

SEN, A. 1990. Development as capability expansion. The community development reader, 4158.

SEN, A. 2001. Development as freedom, Oxford Paperbacks.

SOLARIN, S. A. \& YEN, Y. Y. 2016. A global analysis of the impact of research output on economic growth. Scientometrics, 108, 855-874.

SZOMSZOR, M., PENDLEBURY, D. \& ROGERS, G. 2020. Global Research Report Identifying Research Fronts in the Web of Science: From metrics to meaning. Institute for Scientific Information.

TAN LUC, P., XUAN LAN, P., NHAT HANH LE, A. \& THANH TRANG, B. 2020. A CoCitation and Co-Word Analysis of Social Entrepreneurship Research. Journal of Social Entrepreneurship, 1-16.

THE NATIONAL ASSEMBLY OF VIET NAM 2016. Resolution On Five-Year SocioEconomic Development Plan From 2016 - 2020 The National Assembly of The Socialist Republic of Viet Nam. In: NAM, T. N. A. O. V. (ed.). The National Assembly of Viet Nam.

THI HOA, T. 2020. The effects of corruption on the human capital accumulation process: Evidence from Vietnam. Economics of Transition and Institutional Change, 28, 69-88.

THU, V. H. \& GOTO, D. 2020. Does Microfinance Improve the Household Welfare of Ethnic Minorities? Evidence from Bac Kan Province, Vietnam. Progress in Development Studies, 20, 65-83.

THUY, N. 2020a. Vietnam gov't plans 7\% GDP growth in 2021 - 2025 [Online]. Hanoi Times. Available: $\quad$ http://hanoitimes.vn/vietnam-pm-targets-7-gdp-growth-in-2021-2025socio-economic-plan-311732.html [Accessed October 14 2020].

THUY, N. 2020b. Vietnam gov't targets 2.5\% GDP growth for 2020 [Online]. Hanoi Times. Available: $\quad$ http://hanoitimes.vn/vietnam-govt-targets-25-gdp-growth-for-2020314101.html\#: :text=Vietnam $\% 20$ gov't $\% 20$ targets $\% 202.5 \% 25 \% 20$ GDP $\% 20$ growth $\% 20$ for $\% 202020$ \&text $=$ The $\% 20$ GDP $\% 20$ growth $\% 20$ is $\% 20$ expected,minister $\% 20$ of \%20Planning\%20and\%20Investment. [Accessed October 14 2020].

TODARO, M. P. \& SMITH, S. C. 2012. Economic development. Boston, Mass.: AddisonWesley.

TRAN, B. X., DO, H. P., HALL, B., LATKIN, C. A., NGUYEN, T. Q., NGUYEN, C. T., HO, C. S. \& HO, R. C. 2019a. The Use of Health Behavioral Theories in HIV/AIDS Research: A Bibliometric Analysis (Gap Research). AIDS Reviews, 21, 93-107.

TRAN, B. X., NGUYEN, L. H., PHAM, N. M., VU, H. T. T., NGUYEN, H. T., PHAN, D. H., HA, G. H., PHAM, H. Q., NGUYEN, T. P., LATKIN, C. A., HO, C. S. H. \& HO, R. 
C. M. 2020a. Global Mapping of Interventions to Improve Quality of Life of People with Diabetes in 1990-2018. International Journal of Environmental Research and Public Health, 17, 1597.

TRAN, B. X., NGUYEN, L. H., TURNER, H. C., NGHIEM, S., VU, G. T., NGUYEN, C. T., LATKIN, C. A., HO, C. S. H. \& HO, R. C. M. 2019b. Economic evaluation studies in the field of HIV/AIDS: bibliometric analysis on research development and scopes (GAPRESEARCH). BMC Health Services Research, 19, 834.

TRAN, T., HOANG, K.-L., LA, V.-P., HO, M.-T. \& VUONG, Q.-H. 2020b. Scrambling for higher metrics in the Journal Impact Factor bubble period: a real-world problem in science management and its implications. Problems and Perspectives in Management, $18,48-56$.

TRAN, T. Q., NGUYEN, C. V. \& VAN VU, H. 2018a. Does Economic Inequality Affect the Quality of Life of Older People in Rural Vietnam? Journal of Happiness Studies, 19, 781-799.

TRAN, T. Q., NGUYEN, S. H., VU, H. V. \& NGUYEN, V. Q. 2015. A note on poverty among ethnic minorities in the Northwest region of Vietnam. Post-Communist Economies, 27, 268-281.

TRAN, T. Q., TRAN, A. L., PHAM, T. M. \& VAN VU, H. 2018b. Local governance and occupational choice among young people: First evidence from Vietnam. Children and Youth Services Review, 86, 21-31.

TRANG, N. T. T. 2020. The status quo of Vietnam's productivity and some solutions for enhancing the productivity. Industry and Trade Magazine, 12.

TUNG, D. T. 2017. Measurement of on-farm diversification in Vietnam. Outlook on Agriculture, 46, 3-12.

VAN KHUC, Q., LE, T.-A. T., NGUYEN, T. H., NONG, D., TRAN, B. Q., MEYFROIDT, P., TRAN, T., DUONG, P. B., NGUYEN, T. T., TRAN, T., PHAM, L., LEU, S., THAO, N. T. P., HUU-DUNG, N., DAO, T.-K., VAN HONG, N., NGUYET, B. T. M., NGUYEN, H.-S. \& PASCHKE, M. W. 2020. Forest Cover Change, Households' Livelihoods, Trade-Offs, and Constraints Associated with Plantation Forests in Poor Upland-Rural Landscapes: Evidence from North Central Vietnam. Forests, 11, 548.

VAN THANG, N. \& FREEMAN, N. J. 2009. State-owned enterprises in Vietnam: are they 'crowding out' the private sector? Post-Communist Economies, 21, 227-247.

VUONG, Q.-H. 2018. The (ir)rational consideration of the cost of science in transition economies. Nature Human Behaviour, 2, 5-5.

VUONG, Q.-H., DO, M.-T., PHAM, T.-V.-A., DO, T.-A., DOAN, P.-T., HOANG, A.-D., TA, T.-H., LE, Q.-A. \& PHAM, H.-H. 2020a. The status of educational sciences in Vietnam: A bibliometric analysis from clarivate Web of Science database between 1991 and 2018. Problems of Education in the 21st Century, 78, 644-662.

VUONG, Q.-H., HO, M. T., VUONG, T.-T., NAPIER, N. K., PHAM, H. H. \& NGUYEN, H. V. 2017a. Gender, age, research experience, leading role and academic productivity of Vietnamese researchers in the social sciences and humanities: exploring a 2008-2017 Scopus dataset. European Science Editing, 43, 51 - 55.

VUONG, Q.-H., HO, T. M. \& LA, P. V. 2019. 'Stargazing' and p-hacking behaviours in social sciences: some insights from a developing country. European Science Editing, 45, 54 -55 .

VUONG, Q.-H., HO, T. M., VUONG, T.-T., NGUYEN, H. V., NAPIER, N. K. \& PHAM, H.H. 2017b. Nemo Solus Satis Sapit: Trends of Research Collaborations in the Vietnamese Social Sciences, Observing 2008-2017 Scopus Data. Publications, 5, 24. 
VUONG, Q.-H., LA, V.-P., NGUYEN, M.-H., HO, M.-T., HO, M.-T. \& MANTELLO, P. 2020b. Improving Bayesian statistics understanding in the age of Big Data with the bayesvl R package. Software Impacts, 4, 100016.

VUONG, Q.-H., LA, V.-P., NGUYEN, M.-H., HO, M.-T., TRAN, T. \& HO, M.-T. 2020c. Bayesian analysis for social data: A step-by-step protocol and interpretation. Methods $X$, 7, 100924.

VUONG, Q.-H., LA, V.-P., VUONG, T.-T., HO, M.-T., NGUYEN, H.-K. T., NGUYEN, V.H., PHAM, H.-H. \& HO, M.-T. 2018a. An open database of productivity in Vietnam's social sciences and humanities for public use. Scientific Data, 5, 180188.

VUONG, Q.-H., LA, V.-P., VUONG, T.-T., NGUYEN, H.-K. T., HO, M.-T. \& HO, M.-T. 2020d. What have Vietnamese scholars learned from researching entrepreneurship? A Systematic review. Heliyon, 6, e03808.

VUONG, Q.-H., NAPIER, N. K., HO, T. M., NGUYEN, V. H., VUONG, T.-T., PHAM, H. H. \& NGUYEN, H. K. T. 2020e. Effects of work environment and collaboration on research productivity in Vietnamese social sciences: evidence from 2008 to 2017 scopus data. Studies in Higher Education, 44, 2132-2147.

VUONG, Q. H. 2014. Vietnam's political economy: A discussion on the 1986-2016 period Centre Emile Bernheim, Université Libre de Bruxelles, CEB Working Paper $\mathrm{N}^{\circ} 14 / 010$.

VUONG, Q. H. 2020. Reform retractions to make them more transparent. Nature, 582, 149.

VUONG, Q. H., LA, V. P., VUONG, T. T., HOANG, P. H., HO, M. T., HO, M. T. \& NGUYEN, H. K. T. 2020f. Multi-faceted insights of entrepreneurship facing a fastgrowing economy: A literature review. Open Economics, 3, 25.

VUONG, Q. H. \& NANCY, K. N. 2014. Resource curse or destructive creation in transition: Evidence from Vietnam's corporate sector. Management Research Review, 37, 642657.

VUONG, Q. H. \& TRAN, T. 2019. The Vietnamese Social Sciences at a Fork in the Road Warsaw, Poland, De Gruyter.

VUONG, T.-T., HO, M.-T., NGUYEN, M.-H., NGUYEN, T.-H. T., NGUYEN, T.-D., NGUYEN, T.-L., LUONG, A.-P. \& VUONG, Q.-H. 2020g. Adopting open access in the social sciences and humanities: evidence from a developing nation. Heliyon, 6, e04522.

VUONG, T.-T., NGUYEN, H. K. T., HO, T. M., HO, T. M. \& VUONG, Q.-H. 2018b. The (In)Significance of Socio-Demographic Factors as Possible Determinants of Vietnamese Social Scientists' Contribution-Adjusted Productivity: Preliminary Results from 2008-2017 Scopus Data. Societies, 8, 3.

WALDER, A. G. \& NGUYEN, G. H. 2008. Ownership, Organization, and Income Inequality: Market Transition in Rural Vietnam. American Sociological Review, 73, 251-269.

WORLD BANK. 2020. Household Living Standards Survey 2004 [Online]. World Bank. Available: https://microdata.worldbank.org/index.php/catalog/2370 [Accessed October 25 2020]. 